Portland State University

PDXScholar

$1-1-2011$

\title{
Assessment of an Optimal Bus Stop Spacing Model Using High Resolution Archived Stop-Level Data
}

Huan Li

Portland State University

Follow this and additional works at: https://pdxscholar.library.pdx.edu/open_access_etds Let us know how access to this document benefits you.

\section{Recommended Citation}

Li, Huan, "Assessment of an Optimal Bus Stop Spacing Model Using High Resolution Archived Stop-Level Data" (2011). Dissertations and Theses. Paper 244.

https://doi.org/10.15760/etd.244

This Thesis is brought to you for free and open access. It has been accepted for inclusion in Dissertations and Theses by an authorized administrator of PDXScholar. Please contact us if we can make this document more accessible: pdxscholar@pdx.edu. 


\section{Assessment of an Optimal Bus Stop Spacing Model Using High Resolution Archived Stop-Level Data}

by

\section{Huan Li}

A thesis submitted in partial fulfillment of the requirements for the degree of

Master of Science

in

Civil and Environmental Engineering

Thesis Committee:

Christopher M. Monsere, Chair

Miguel A. Figliozzi

Kelly Clifton

\section{Portland State University}

(C)2011 


\begin{abstract}
In practice, the design of bus routes and stop placement involves calculated tradeoffs between service frequency, quality, and access. Increased stop density improves access but contributes to slow operating speeds and increased operating costs. In this thesis, a optimized bus stop spacing model is applied using the high resolution archived stop-level bus performance data from the Bus Dispatch System (BDS) provided by TriMet, the regional transit provider for the Portland metropolitan area.. Two cost components are considered in the stop spacing model including passenger access cost and in-vehicle passenger stopping cost, and are combined and optimized to minimize total cost. A case-study is presented using one year's stop-level data from one bus route 19 in Portland, Oregon. The analysis considered both inbound and outbound stop spacing and determined the optimal average stop spacing based on an all-day, peak and off-peak time periods. Based on the analysis considering inbound trips over the entire day, the theoretical optimized bus stop spacing was about 1,200 feet, as compared to the current value of 890 feet. This paper also builds on the all day analysis and focuses on inbound and outbound trips during peak periods, resulting in optimized spacing of about 1,300 feet. The peak hour demand has a significant impact on the transit operation. A bus stop consolidation scheme is proposed for the analyzed bus route considering the peak hour transit demand. Finally, the thesis discusses trade-offs and presents an estimate of transit operating cost savings based on the optimized spacing. Given the growing availability of high-resolution archived data, the thesis illustrates that this
\end{abstract}


modeling tool can be applied in a routine way across multiple routes as part of an ongoing service planning and performance measurement process. 


\section{ACKNOWLEDGEMENTS}

I would like to express my gratitude to all those who gave me the possibility to complete this thesis. I am deeply indebted to my mentor and role model, Prof. Robert L. Bertini from the Department of Civil and Environmental Engineering at Portland State University for his encouragement, patience, and guidance throughout the course of this research. My career has been strongly influenced by his dedication to excellent research work and his passion for the field of operations research and transportation science. I have furthermore to thank ITS lab mates and other faculties, my family and friends who encouraged me to go ahead with my thesis.

I want to thank my professor Dr. Monsere for giving me permission to commence, guide and support this thesis in the first instance, to do the necessary research work, and thank TriMet for generously providing the data.

My lab mates and other faculty member Dr. Figliozzi from ITS lab supported me in my research work as well. I want to thank them for all their help, valuable hints and technical communications. Especially, I would like to give my special thanks to my parents whose patient love enabled me to complete this work and my study in Portland State University. They were of great help in my difficult times. 
TABLE OF CONTENTS

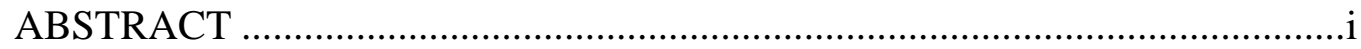

ACKNOWLEDGEMENTS ..................................................................... iii

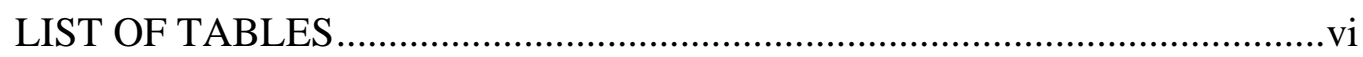

LIST OF FIGURES …..................................................................... vii

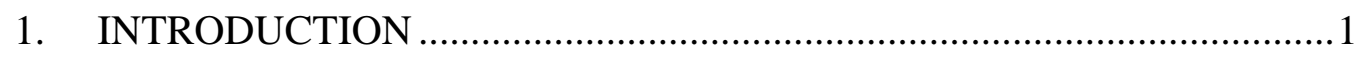

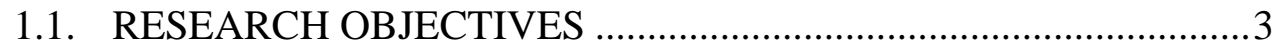

1.2. THESIS OVERVIEW ........................................................

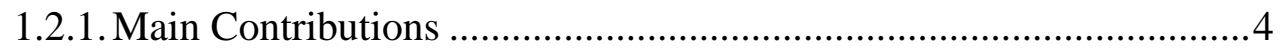

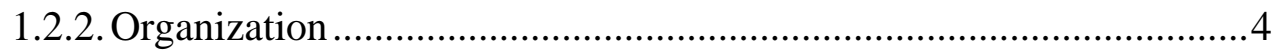

2. LITERATURE REVIEW ............................................................6

2.1. STOP LOCATION AND SPACING .........................................6

2.2. VALUE OF TIME ................................................................. 9

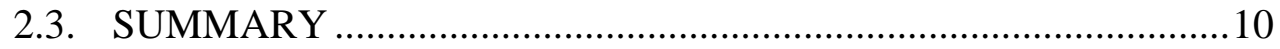

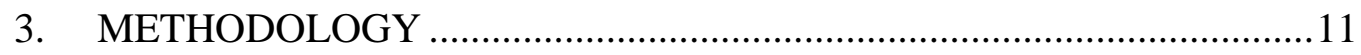

3.1. MODEL DESCRIPTION ........................................................... 14

3.2. DATA DESCRIPTION .......................................................20

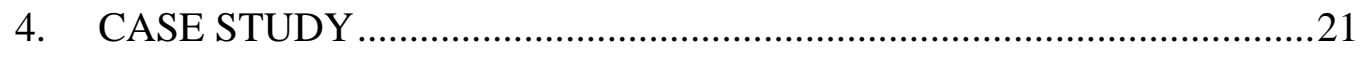

4.1. ROUTE DESCRIPTION AND CURRENT SPACING ANALYSIS22

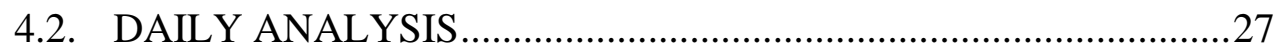

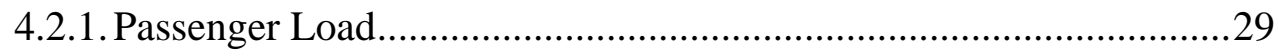




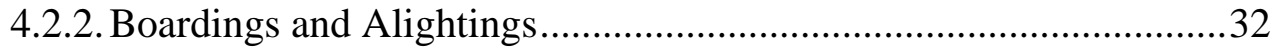

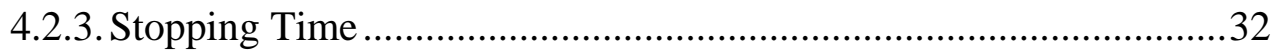

4.2.4. Optimized Stop Spacing ............................................................. 33

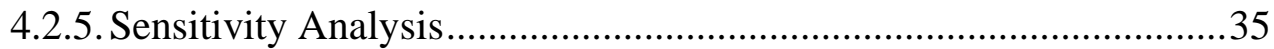

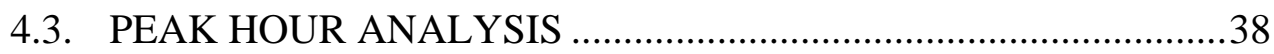

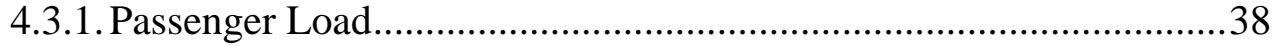

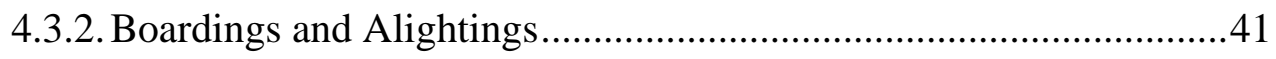

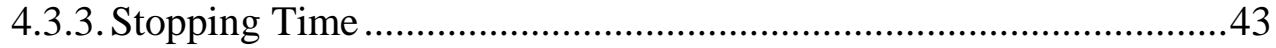

4.3.4. Optimized Stop Spacing ...................................................... 44

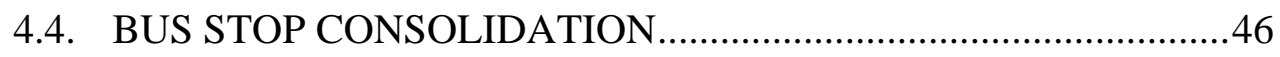

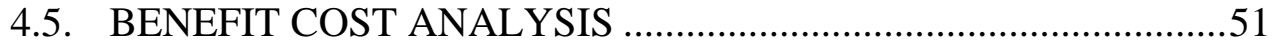

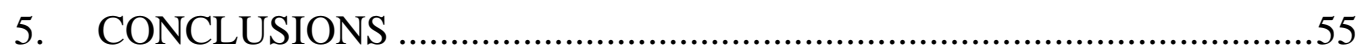

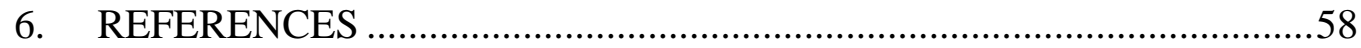




\section{LIST OF TABLES}

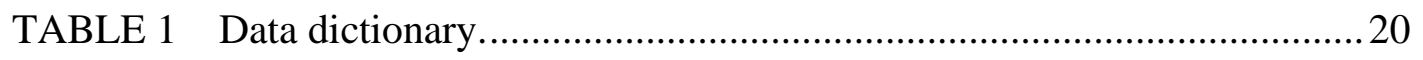

TABLE 2 Basic almanac of the studied inbound Route 19...............................28 TABLE 3 Sensitivity analysis for the optimized spacing based on all day analysis

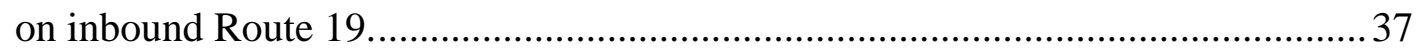

TABLE 4 Route 19 peak hour data almanac for both inbound and outbound

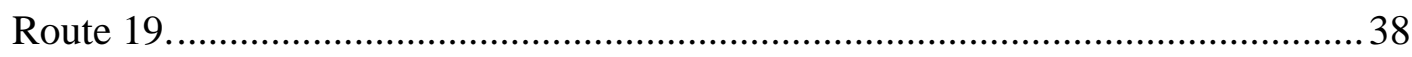

TABLE 5 Values of variables in spacing optimization model. ........................ 44

TABLE 6 Values of optimized spacing summary..................................... 46

TABLE 7 Bus stop consolidation example on first a few stops on outbound Route 19.

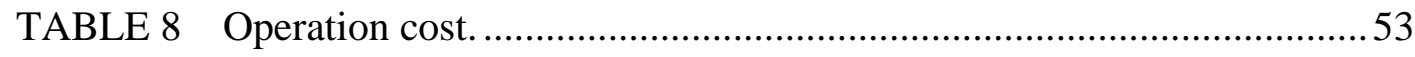

TABLE 9 Sensitivity analysis for the optimized spacing based on peak hour

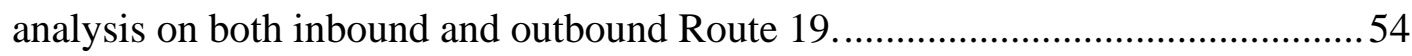




\section{LIST OF FIGURES}

FIGURE 1 Concept of spacing optimization.................................................... 11

FIGURE 2 Two dimensional plane of bus stop accessibility ................................. 12

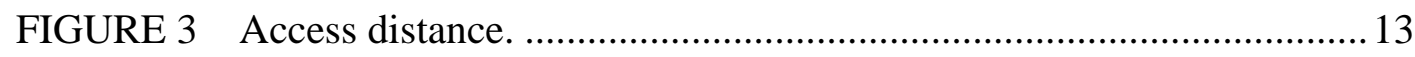

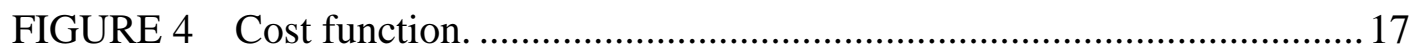

FIGURE 5 Model function approximation............................................................ 18

FIGURE 6 Total cost function description......................................................... 19

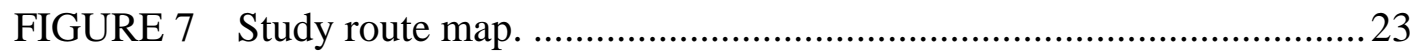

FIGURE 8 Stop spacing distribution, Route 19, Inbound ......................................2

FIGURE 9 Stop spacing distribution, Route 19, Outbound ………………..........25

FIGURE 10 Correlation between passenger load and current spacing for inbound

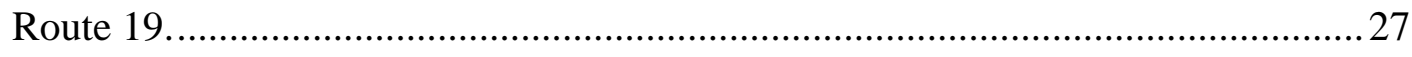

FIGURE 11 Distribution of passengers load for all day analysis on inbound Route

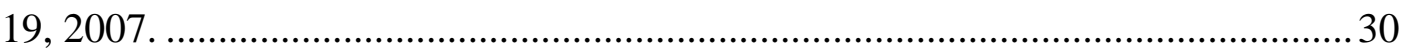

FIGURE 12 Total passenger ons and offs per trip for all day analysis on inbound

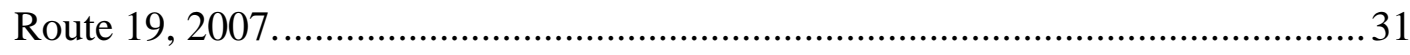

FIGURE 13 Bus trajectory between two stops.................................................. 31

FIGURE 14 Optimized bus stop spacing for inbound Route 19 based on all day

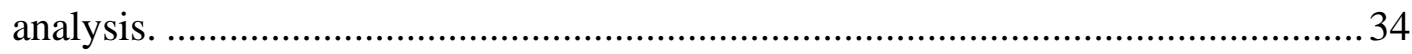

FIGURE 15 Distribution of passenger load for inbound Route 19......................39

FIGURE 16 Distribution of passenger load outbound 19................................... 40 
FIGURE 17 Passenger ons and offs per trip for peak hour analysis on both inbound and outbound Route 19 in the year 2007................................................. 42 FIGURE 18 Passenger arrival rate for peak hour analysis on stop ID 2110 along

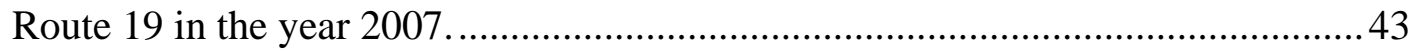
FIGURE 19 Optimized bus stop spacing for Route 19 based on peak hour analysis on both inbound and outbound routes....................................................... 45 FIGURE 20 A comparison of peak hours and off peak hours for spatial distribution of passenger activities for both inbound and outbound Route 19........50

FIGURE 21 Optimal bus stop locations. ............................................................ 51 


\section{INTRODUCTION}

In practice, the design of bus routes and stop placement involves calculated tradeoffs between service frequency, quality, and access. Frequent stops allow short walking distance for transit customers and, in some cases, attract more riders. However, each stop imposes delays to through riders and increase operating costs (overall route travel times increase with each stop and the acceleration and deceleration imposes additional wear and tear and fuel use). At some stop locations, it may also be difficult for a bus to re-enter the traffic stream during congested periods. Finally, each stop increases crash risk for maneuvering back in to the traffic stream. Clearly, there is a trade-off between providing sufficient access to the public transit system and stopping too frequently.

Transit planners generally favors bus stop accessibility, sometimes based on past history and tradition rather than rigorous ongoing analysis at the stop level (1-

7). The bus stop placement is normally based on land use characteristics and population densities, and considers the prospective transit riders in the area. The more employment and population, the more potential transit riders are assumed in the planning perspective, thus, access to transit is needed in the area. It is generally held that bus stops are too close to one other on many routes, slowing bus operations and increasing operation expenditures. On the other hand, by reducing the number of stops, transit operators risk making their service inaccessible in perception and/or reality, which may lead to loss of patrons when bus stops are 
moved or distantly spaced to avert the problems associated with closely spaced stops. This type of bus stop deployment scheme, which is adopted by many agencies, primarily considers providing a high level of access but ignores the potential cost from running cost caused by frequent bus stops. A high density of bus stops also contributes to slow bus speed, and consequently increases operational costs.

Thus, some transit operation agencies in the U.S. (1-7) conducted studies on bus stops spacing to improve the guidelines for bus stop deployments. Furth (5) suggests that the optimal solution was an average stop spacing of 1,300 ft, in sharp contrast to the actual average spacing of $650 \mathrm{ft}$ in Boston. The San Francisco Municipal Transportation Agency (SFMTA) also studied bus stop locations and found that the existing SFMTA stop spacing policy does not consider delay to onboard customers or customer activity at each stop (27). SFMTA recommended that their stop spacing standard should be $800 \mathrm{ft}$ to $1000 \mathrm{ft}$ where the road grade is less than $10 \% ; 500 \mathrm{ft}$ to $600 \mathrm{ft}$ where the road grade is between $10 \%$ and $15 \% ; 300$ $\mathrm{ft}$ to $400 \mathrm{ft}$ where the road grade is more than $15 \%$. However, in their study, it is summarized that there are $70 \%$ bus stops are under guideline, $13 \%$ stops exceed guideline and only $17 \%$ stops meet the guideline. The improvement of the current policy and guideline is proposed to consider access issues and delay to onboard customers. SFMTA also emphasizes that the stop consolidation needs to meet the policy guidelines, and the stop spacing policy should consider delays to onboard customers. In Portland, Oregon, similar issues arose and were addressed by the 
local transit agency, TriMet. TriMet's service standards (22) call for a stop spacing of $780 \mathrm{ft}$ in fully developed residential areas $22-80$ units/acre and $1000 \mathrm{ft}$ in low density residential 4-22 units/acre. In Portland an analysis of a corridor on which stop consolidation had been applied was conducted in order to measure the costs and benefits of such a program (9). As an example, revisions to the transit mall in 2007 in downtown Portland consolidated stops to improve travel times in the mall. As suggested by these concerns, a simple model is needed to serve transit agencies for policy making which considers the arising spacing issues that primarily need to consider the delays to onboard customers.

\subsection{RESEARCH OBJECTIVES}

The transit service objectives, principles and standards established by local transit agencies are intended to reflect the underlying values of the residents. It means that a meaningful expression of the performance for the transit system is desired to reflect the values for transit riders. With this goal, to reduce the user cost for transit riders is determined as the objective function. This thesis describes the application of an optimal stop spacing model (10) within the constraints of access and riding costs with the objective of minimizing the total user cost. The optimal stop spacing considers passenger activities at a stop through the user cost. This theoretical exercise uses a rich set of TriMet's archived stop-level data from one route (Route 19) as a case study. The data analysis included all day transit demand and peak hour transit demand. Based on calculated optimal stop spacing, a bus stop 
consolidation scheme will be proposed considering spacing distribution of transit demand along this route.

\subsection{THESIS OVERVIEW}

\subsubsection{Main Contributions}

Previous research that investigated the bus stop deployment primarily focused on the theoretical description of bus stop spacing concept and principles, without the use of empirical data for model validation. In this thesis, a bus stop spacing model is formulated based on an optimization concept and a number of assumptions for simplifying the formulation. The thesis then applies the model framework using a case study is done with the use of a year's worth of stop-level archived data. The main contributions of this thesis include:

1. Application of an optimized bus stop spacing model using archived stop level data;

2. Perform sensitivity analysis on the user cost with the optimized stop spacing;

3. Discuss on the benefit cost of optimizing stop spacing, and estimate the potential savings on the operation cost.

\subsubsection{Organization}

The remaining chapters of the thesis are organized as follows. Chapter Two will provide a review on the methodologies used in previous researches and discuss the 
passenger's value of time which will be implemented in the user cost which will be used as objective function.

Chapter Three will provide a theoretical relationships between stop spacing and the key factors in the optimization for this thesis. After investigating the cost function of stop spacing, a closer look will be taken as the link between the spacing and total cost as an optimization scheme. The access cost and riding cost will be derived conceptually for formulating the cost function with variable of spacing. In this chapter, the details of data set is also described which will be used in this model analysis. Detailed information of the available data set will be provided for calculating the values in the model.

Chapter Four will apply the archived stop level data on the model as a case study on bus Route 19 in Portland, Oregon for both daily analysis and peak hour analysis. All the variables used in the model and their impacts on the value of spacing will be statistically analyzed. Then, the model based optimal bus stop spacing will be provided based on both daily analysis and peak hour analysis. A bus stop consolidation scheme will be provided based on the model analysis results. The benefit and cost of closing some bus stops will be estimated as well.

This thesis concludes with chapter Five where the conclusions are drawn and discussed, and where propositions for potential further investigation are presented. 


\section{LITERATURE REVIEW}

In this chapter, an overview of the methodologies used for optimizing bus stop location and spacing in previous researches is first presented. Next, a brief literature review of user cost, the value of passenger's riding time and waiting time are presented. Finally, the chapter includes with a summary.

\subsection{STOP LOCATION AND SPACING}

The operational effect of bus-stop spacing has been a critical issue. Closely spaced bus stops disrupt the traffic flow on the bus route, particularly during peak hours because buses make frequent stops to provide services to customers. There are some research on the optimal bus stop spacing through different strains and different methods. Furth, P G and Rahbee, A. (5) studied the optimal bus stop spacing though dynamic programming and geographic modeling. A simple geographic model was used to distribute the demand observed at existing stops to cross-streets and parallel streets in the route service area, resulting in a demand distribution that included concentrated and distributed demands. Dynamic programming algorithm was used to determine the optimal bus-stop locations. A bus route in Boston was modeled, in which the optimal solution was an average stop spacing of $400 \mathrm{~m}$ (4 stops/mi), in sharp contrast to the existing average spacing of $200 \mathrm{~m}$ (8 stops/mi). 
Anthony A. Saka (8) built a model for Determining Optimum Bus-Stop Spacing in Urban Areas. The proposed model is derived from the fundamental relationships that exist among velocity, uniform acceleration and deceleration, displacement, and among the average bus operating speed, headway, required fleet size, and potential system capacity.

The shorter bus stop spacing also results in energy loss, increased delay/congestion, transit fleet-size requirement and mobile emissions. Anthony A. Saka (23) describes a set of analytical models developed to assess the effect of busstop spacing on travel time and mobile emissions in urban areas. As part of the study, a nationwide survey of transit agencies was conducted to determine the prevalent bus-stop spacing policy in urban areas. The survey results show that the average bus stop spacing was approximately 330 meters $(\mathrm{m})$, which is much less than the optimal threshold of approximately $700 \mathrm{~m}$ to $800 \mathrm{~m}$ obtained from the models. The analysis shows that for a typical bus route in an urban area, the peak hourly reduction in mobile emissions from optimal spacing of bus stops is not considered substantial for hydrocarbon, Nitrogen oxides, and carbon monoxide, which actually increased.

Some of cities in US have evaluated the proper bus stop spacing response to improve bus service. Kemp, M A (25) discussed an analysis of data describing 40 months' operating experience for the San Diego Transit Corporation bus system. The analysis used a simultaneous-equations model estimated by using a 
pooled time-series/ cross-sectional data base. The model relates the ridership on a specific bus route in a specific month to various influencing factors, particularly the service and fare policies adopted by the system.

Ercolano, J M (26) evaluated limited-stop bus operations in New York City's borough of Manhattan by comparing performance characteristics and passenger use to those of local service on the same routes. Among the types of service-related cost savings cited from employing limited scheduling, annual savings from peak vehicle reductions amount to more than 60 percent of total possible economies expected through using limited bus runs for roughly half the peak period trips on suitable routes. Two sets of bivariate regression models were computed and calibrated to serve as general sketch-planning guides for reviewing routes that may benefit from limited-service implementation. Five warrants explaining what service revisions and performance modifications are essential if limited bus operations are to be feasibly used to cut costs and attract ridership are presented.

\section{El-Geneidy Ahmed M, Strathman James G, Kimpel Thomas J and Crout} David T (9) used the TriMet data to evaluate effects of bus stop consolidation on passenger activity and transit operations. This research addressed changes in passenger activity and operating performance after implementation of a bus stop consolidation project at TriMet, the regional transit provider for the Portland, Oregon, metropolitan area. The findings indicated that bus stop consolidation had no significant effects on passenger activity, whereas bus running times improved 
by nearly $6 \%$. Running time improvements may have been limited by insufficient schedule adjustments.

The most famous study on bus spacing is done by Gordon F. Newell (10) that it derives a concept of optimizing bus stop spacing with the use of user cost. This study not only provides some quick calculations on the performance of a bus route, but also discusses the operational factors at stop level including the time lost for a bus start and stop, passenger influences on vehicle trip time based on the vehicle trajectory analysis. Besides, the discussion is also expanded to network level that the economies of scale in land use and transportation. These are all valuable methodologies for studying the delay to onboard customers and its impact on bus travel time in microscopic perspective. In this thesis, the model concept is derived from his study with the goal of minimizing user cost which will be discussed in the next session.

\subsection{VALUE OF TIME}

User cost has been used as many optimization objective function, especially for the topic here with the goal of minimizing the cost by optimizing bus spacing. In transportation planning, the value of time is an important assumption which is applied as default value. The current total user cost can be estimated assuming a value of $\$ 16 / \mathrm{hr}$ for access cost (waiting + walking) and $\$ 8 / \mathrm{hr}$ for the riding cost (24). Travel time is generally valued at half of the average wage rate and two or three times higher for time spent driving in congestion, walking to a transit stop, 
waiting for a bus, or traveling in unpleasant conditions such as in a crowded vehicle (24). This translates to a cost per passenger per unit length of $\$ 1.06$ for the inbound access cost and $\$ 2.79$ for the inbound riding cost, and of $\$ 0.95$ for the outbound access cost and $\$ 2.38$ for the outbound riding cost. The higher riding cost is due to time lost at more than the optimal number of stops while the lower access cost indicates that the bus stops frequency provided a higher level of accessibility.

\subsection{SUMMARY}

In summary, most of methodologies used for bus transit service are for planning perspectives rather that its operation. The majority of them are complex models which are hard for practical and field implementation. In this thesis, the goal is to present a simple approach to provide a referenced optimized spacing for practitioners with the use of archived field data which can help solve the existing stop location problem immediately. The objective of minimizing user cost used in this thesis is also different to other methods, that in order to include the stop level passenger activities which is normally ignored by many public agencies when

deploy bus stop spacing policy as stated in previous chapter. 


\section{METHODOLOGY}

The operational effects of bus stop spacing are critical in public transportation operations. Transit operators must balance many objectives and constraints when placing bus stops. Closely spaced bus stops provide short distances for passenger access (11-12) but increase overall trip times (13). Large bus stop spacing minimizes passenger in-vehicle time but reduces the accessibility of the system. Stop spacing has been studied in terms of minimizing transit user's time, and evaluating trade-offs between access and in-vehicle time $(5,8,11,14-17)$. In particular, based on Newell's concept (10), an aggregate total cost function was developed including:

- Minimizing access cost $C_{a}$ which favors small spacing

- Minimizing riding cost $C_{r}$ which favors large spacing

The total cost of access and riding per unit length is convex in stop spacing $s$ and can be minimized as shown in Figure 1. The cost over some trip length $L$ can be minimized by minimizing cost per unit length.

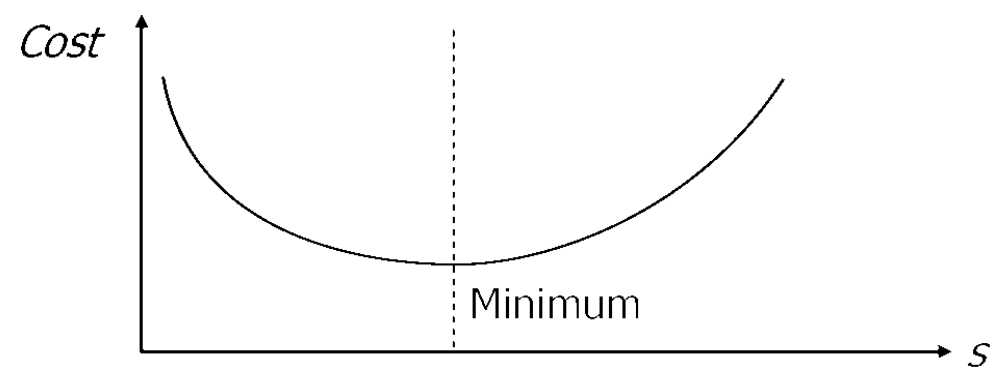

FIGURE 1 Concept of spacing optimization. 
Dimensional analysis is used to set up equations in terms of a dimensionless parameter ps, where:

$p s=$ Expected number of passengers boarding and alighting per stop;

$s=$ Stop spacing $($ distance $)$

$p=$ Density of trip origins plus density of trip destinations for passengers who board the same bus (number of boardings and alightings /distance).

The objective function is examined for choosing $s$. The trip origins and destinations are considered to be distributed in a two-dimensional plane. As shown in Figure 2, to travel to a stop, a passenger walks both perpendicular and parallel to the route.

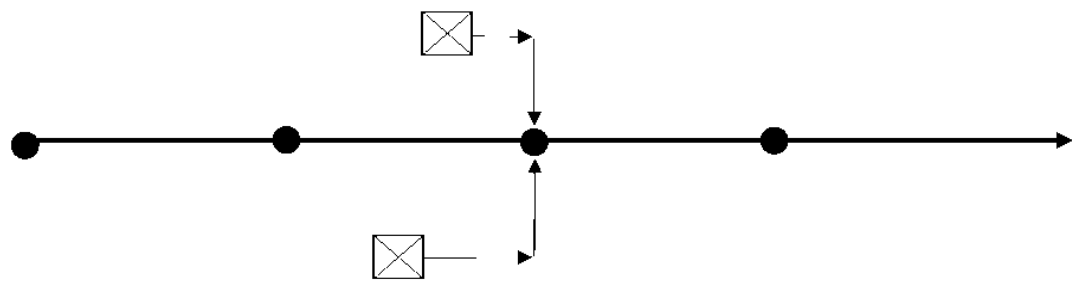

FIGURE 2 Two dimensional plane of bus stop accessibility.

For optimizing stop spacing, the model is based on several assumptions (4):

- Number of passengers boarding or alighting at a stop is Poisson distributed; 
- $\operatorname{Pr}[$ number of boarding and alighting $=\mathrm{x}]$ is approximately Poisson distributed;

- $\mathrm{E}$ [number of boarding or alighting $]=p s$;

- The probability that vehicle does not stop (no passenger wants to board or alight $)=1-\operatorname{Pr}[$ number boarding and alighting $=0]=e^{-p s}$ $(x=0)$, so $\operatorname{Pr}=1-e^{-p s}$;

- Travel demand is uniformly distributed over $s$;

- For analyzing spacing, origins and destinations are considered to be distributed along the route in one dimension. The perpendicular access is ignored since it is the same no matter where the stops are located;

- Average access distance (parallel only) $l=\frac{s}{4}$, as shown in Figure 3 .

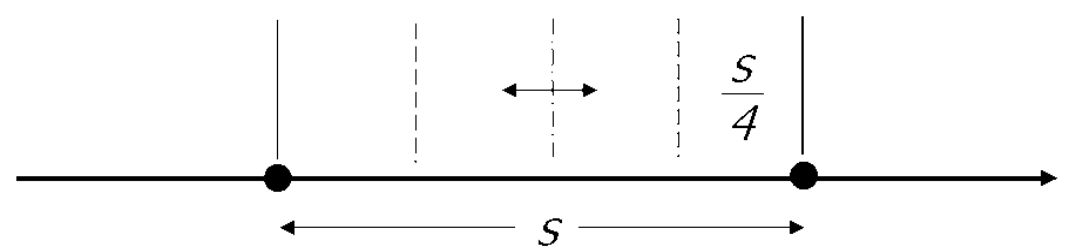

FIGURE 3 Access distance.

Based on this basic model conceptualized by Newell $(10,14)$, the spacing of a TriMet bus route is examined using archived Bus Dispatch System (BDS). An optimal spacing is computed for the route as a basis for transit service improvement and a sensitivity analysis is performed aimed at assessing the costs and benefits of changing the stop spacing. This framework is aimed at demonstrating that a rich set 
of archived stop-level data can facilitate useful and regular assessments of transit service (18).

\subsection{MODEL DESCRIPTION}

Again after Newell (10), the total cost expression is formulated with two cost components:

- Access cost

- $\quad$ Riding and stopping cost

The access cost depends on the number of passenger boardings and alightings at each stop, and on the access speed $v$. Stop spacing impacts passenger walking distance. Thus, the cost is formulated by unit distance. The unit of each variable should be uniform when inputting the actual number. According to the previous assumptions, the access cost $C_{a}$ over an interval of length $\mathrm{s}$ is:

$$
C_{a}=n l \lambda_{a}=[p s] \times\left[\frac{s}{4}\right] \times\left[\frac{\gamma_{a}}{v}\right]=\frac{p s^{2} \gamma_{a}}{4 v}
$$

Where:

$$
C_{a}=\text { Access cost }
$$

$n=$ Average number of passenger boarding and alighting per stop $=p s$; 
$l=$ Average distance travelled $\frac{s}{4}$;

$\lambda_{a}=$ Cost per unit distance;

$\gamma_{a}=$ Average cost per unit time per person for access;

$v=$ Access speed.

The riding and stopping cost is comprised of the in-vehicle waiting time for bus passengers during the boarding and alighting time. With closer spacing more time is consumed by the boardings and alightings due to the fixed deceleration and acceleration time needed to stop. The in-vehicle time required for a bus to stop for passenger boarding and alighting is the dwell time plus the lost time due to vehicle deceleration and acceleration. The total riding and stopping $\operatorname{cost} C_{r}$ in an interval of length $\mathrm{s}$ is then:

$$
C_{r}=N\left(t_{r}+t_{l}\right) \lambda_{r}=N \times\left[\frac{s}{V}+\tau P_{r}\right] \times\left[\gamma_{r}\right]=\frac{N s \gamma_{r}}{V}+N \tau \gamma_{r}\left(1-e^{-p s}\right)
$$

Where:

$N=$ Expected number of passengers on the vehicle;

$t_{r}=$ Riding time;

$t_{l}=$ Lost time; 
$V=$ Vehicle cruise speed;

$\tau=$ Time lost in stopping to serve passengers.

$\gamma_{r}=$ Average cost per unit time per person for riding

$P_{r}=$ Probability that vehicle actually stops $\left(1-e^{-p s}\right)$

The average cost per unit length $\mathrm{s}$ is then:

$$
C=\frac{\left(C_{a}+C_{r}\right)}{s}=\left[\frac{p s \gamma_{a}}{4 v \gamma_{r} \tau p N}+\frac{\left(1-e^{-p s}\right)}{p s}\right] \gamma_{r} \tau p N+\frac{N \gamma_{r}}{V}
$$

Given that $\beta=4 \frac{\gamma_{r}}{\gamma_{a}} v \tau p N$ (unitless);

$\frac{\gamma_{r}}{\gamma_{a}}=$ value of riding time compared to access time $\left(<1\right.$, maybe $\left.\frac{1}{3} \rightarrow \frac{1}{4}\right)$; and

$\tau p N=$ number of passengers with origins or destinations that lie within a distance one can travel by access (walking) in lost time $\tau$.

The average cost per unit length is then:

$$
C=\left[\frac{p s}{\beta}+\frac{\left(1-e^{-p s}\right)}{p s}\right] \gamma_{r} \tau p N+\frac{N \gamma_{r}}{V}
$$


Equation 4 indicates that stop spacing $\mathrm{s}$ is independent of $V$ and $\gamma_{r} \tau N p$.

Therefore, the choice of stop spacing s depends solely on $\beta$. As shown in Figure 4, the optimal s changes with $\beta$. The objective of optimizing stop spacing with the constraint of minimizing the total cost is then:

$$
C_{\mathrm{o}}=\frac{p s}{\beta}+\frac{\left(1-e^{-p s}\right)}{p s}
$$

It is assumed that the total cost $C_{\mathrm{O}}=1$ in equation 5 when the number of passengers $p s$ is zero. The minimized total cost is determined by two functions:

$$
\frac{p s}{\beta} \text { and } \frac{\left(1-e^{-p s}\right)}{p s} \text {. }
$$

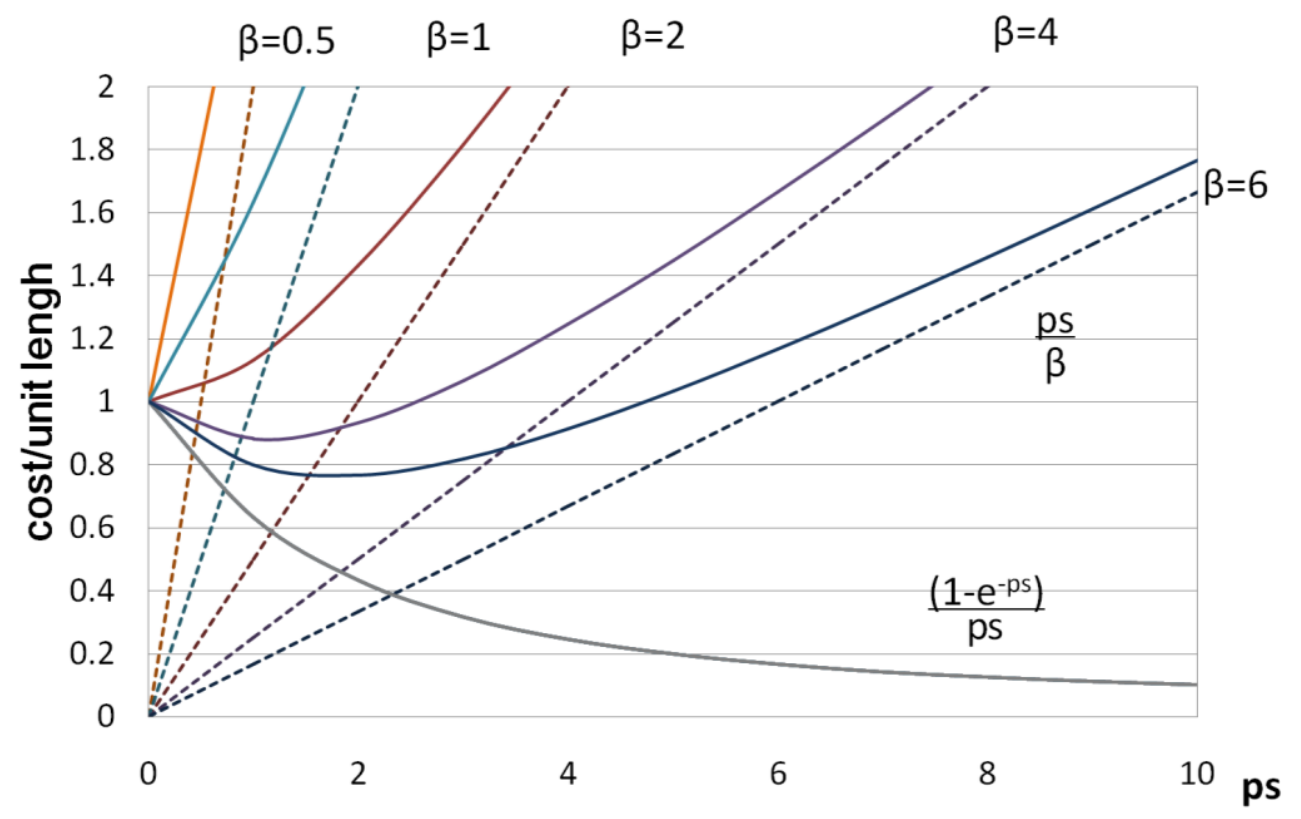

FIGURE 4 Cost function. 
Figure 5 shows that if $\beta<2$, the sum can be increasing at $p s=0$; that is, let passengers on and off wherever they want in a demand-responsive format; if $\beta>2$, then $p s>1$ and $\frac{\left(1-e^{-p s}\right)}{p s}$ can be approximated by $\frac{1}{p s}$, as shown in Figure 5. The total cost reaches a minimum when $\frac{p s}{\beta}$ is equal to $\frac{1}{p s}$. Note that $p s=p s^{*}$ when the total cost reaches the minimum as shown in Figure 6. If $P_{r}$ is treated as 1 for a large $\beta$ :

$$
\frac{1}{p s}=\frac{p s}{\beta} \Rightarrow p s^{*}=\sqrt{\beta} \Rightarrow s^{*}=\frac{\sqrt{\beta}}{p}=\frac{\sqrt{4 \frac{\gamma_{r}}{\gamma_{a}} v \tau N p}}{p}
$$

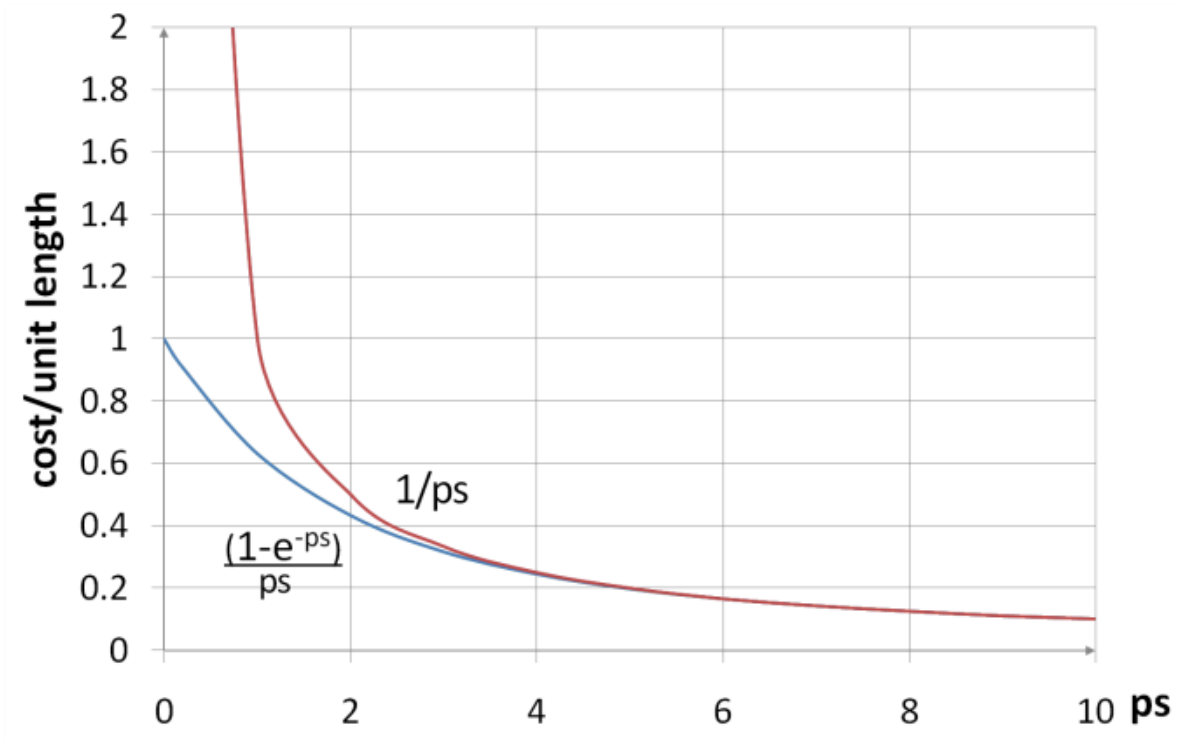

FIGURE 5 Model function approximation. 


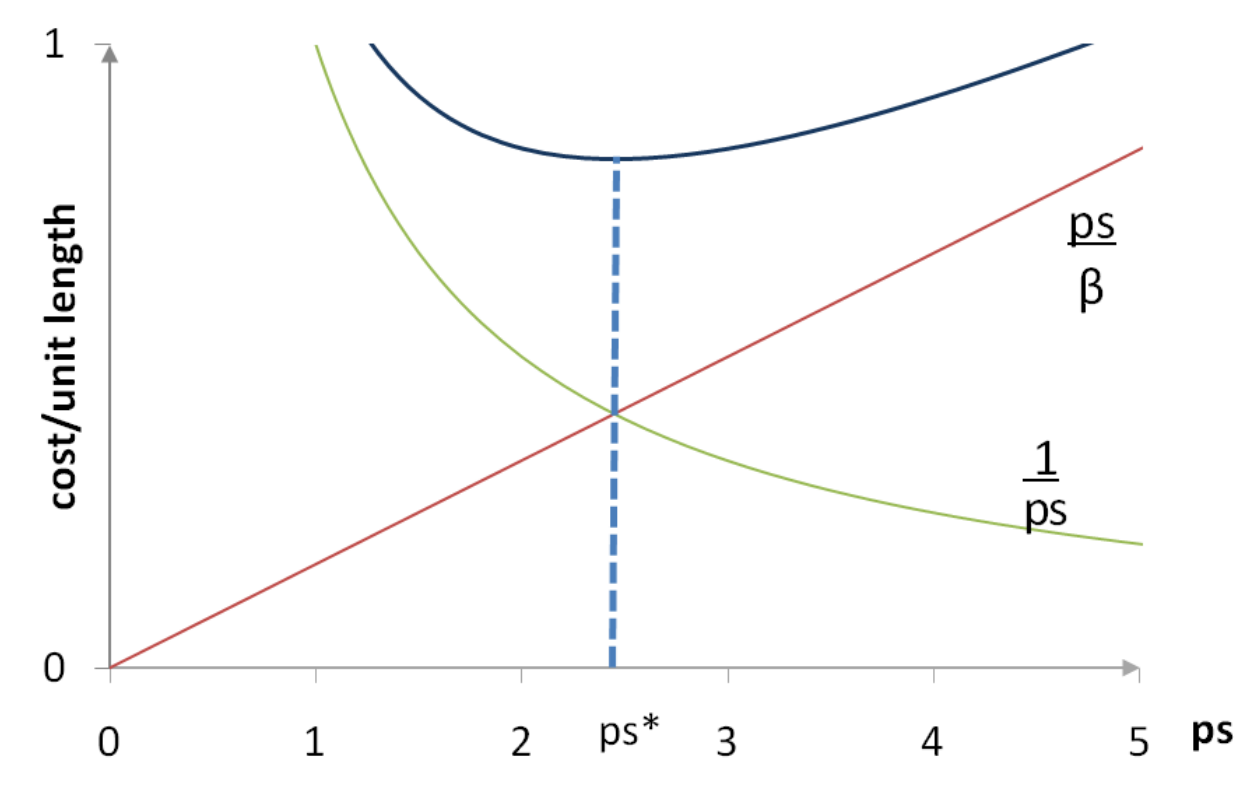

FIGURE 6 Total cost function description.

Note that $4 \frac{\gamma_{r}}{\gamma_{a}}$ is approximately 1 for walking. In addition, walking speed $v$ is approximately $4 \mathrm{ft} / \mathrm{s}$. So the optimal spacing can now be written as:

$$
s=\frac{\sqrt{4 \tau N p}}{p}=\sqrt{\frac{4 \tau N}{p}}
$$

The number of passengers on the bus and the density of origins and destinations are both related to headway $h$. But the effects of $\mathrm{h}$ are cancelled out as shown in equation (7) that only the total number of passengers on vehicle and passenger boardings and alightings per distance are the variables. Thus stop spacing $s$ is independent of $h$ for $\beta>2$. These results will now be used in a case study using high resolution stop-level data for one route. 


\subsection{DATA DESCRIPTION}

TriMet began using an automated bus dispatch system to manage and collect data about the performance of its fleet in the late 1990s. These data provide TriMet with an abundance of useful information that it has used to successfully improve the performance and efficiency of its transit system. Each day, about 700 TriMet buses travel Portland's city and suburban streets on more than 90 different bus routes, collecting data at each scheduled and unscheduled stop. The entire fleet is equipped with the BDS system and about $75 \%$ of the buses also are equipped with automatic passenger counters (APCs). TriMet's BDS database (19-21) includes the following data fields for each stop.

TABLE 1 Data dictionary.

\begin{tabular}{c|l}
\hline Data Element & \multicolumn{1}{c}{ Description } \\
\hline Date & $\begin{array}{l}\text { Service date which is the day of the data record } \\
\text { In assigning trips TriMet blocks the scheduled trips together to form what } \\
\text { is known as a "train," each of which has a unique identification number. } \\
\text { Train }\end{array}$ \\
route number \\
Direction \\
Inbound or outbound (1 is inbound, 0 is outbound) \\
Each trip has a unique number corresponding to all the stops along the \\
trip \\
Arrive Time & time bus arrives at stop and/or time door opens \\
Depart Time & Time bus leaves stop \\
Location & Unique geocoded identification number for each scheduled stop \\
Distance & Odometer reading of cumulative distance traveled (in miles) \\
Max Speed & Maximum speed achieved between stops is recorded (in miles per hour) \\
Dwell & Time door is open \\
Door & Door status (front/rear) \\
Lift & Lift use flag \\
On & Number of passengers boarding (in passengers) \\
Off & Number of passengers alighting (in passengers) \\
Vehicle & Vehicle number \\
Load & Calculated estimated passenger load (in passengers) \\
\hline
\end{tabular}




\section{CASE STUDY}

In this chapter, a case study using Route 19 in Portland, Oregon is presented as an application of the stop spacing model with the use of the archived stop level bus data described above. The outline of this chapter is shown as below:

1) Overview of current spacing issues: as stated in Chapter 1, the major problem for bus stop in some cities is that the current spacing policy ignores the passenger activities at the stop level. In this chapter, this problem is verified by an statistical analysis to observe the correlation of passenger activities and current spacing..

2) All day analysis for inbound route: with the data availability, the major variables in the model is analyzed and calculated with one year's worth of data. The analysis is firstly performed on all day analysis for inbound Route 19. Each variable in the model is analyzed with the archived stop level data to explore the passenger activities at the stop level.

3) Peak hour analysis for both inbound route and outbound route: based on the result, an obvious peak hour passenger activity pattern is unveiled that highest passenger demand is during morning peak hours for inbound Route 19, and that during evening peak hours for outbound Route 19. Then, the preliminary analyses on the model variables are also conducted in order to provide values of those variables in the calculation. Instead, it is focuses on the peak hour passenger activities for both inbound and outbound routes. 
4) Bus stop consolidation and sensitivity analysis: by comparing the optimized spacing from all day analysis and peak hour analysis, the optimization procedure is decided to use the peak hour demand as the basis in order to meet the highest demand during a day. With the optimized spacing, the sensitivity analysis is presented here to show how the model results sensitive to the passenger's value of time.

5) Benefit cost analysis: it is developed to estimate the potential savings on transit operation cost, as the same time.

\subsection{ROUTE DESCRIPTION AND CURRENT SPACING ANALYSIS}

Before the analyses outlined above, the geographic information of Route 19 is described here, and the problem that whether the current spacing considers passenger activities is explored by statistical analysis. As shown in Figure 7, Route 19 follows Glisan St., an arterial parallel to Interstate 84. The land use patterns are visible in the figure, such that the neighborhoods west of NE 20th Ave. are primarily industrial and commercial zoning; however, those to the east of NE 20th Ave. are mainly multi and single family zoning. 


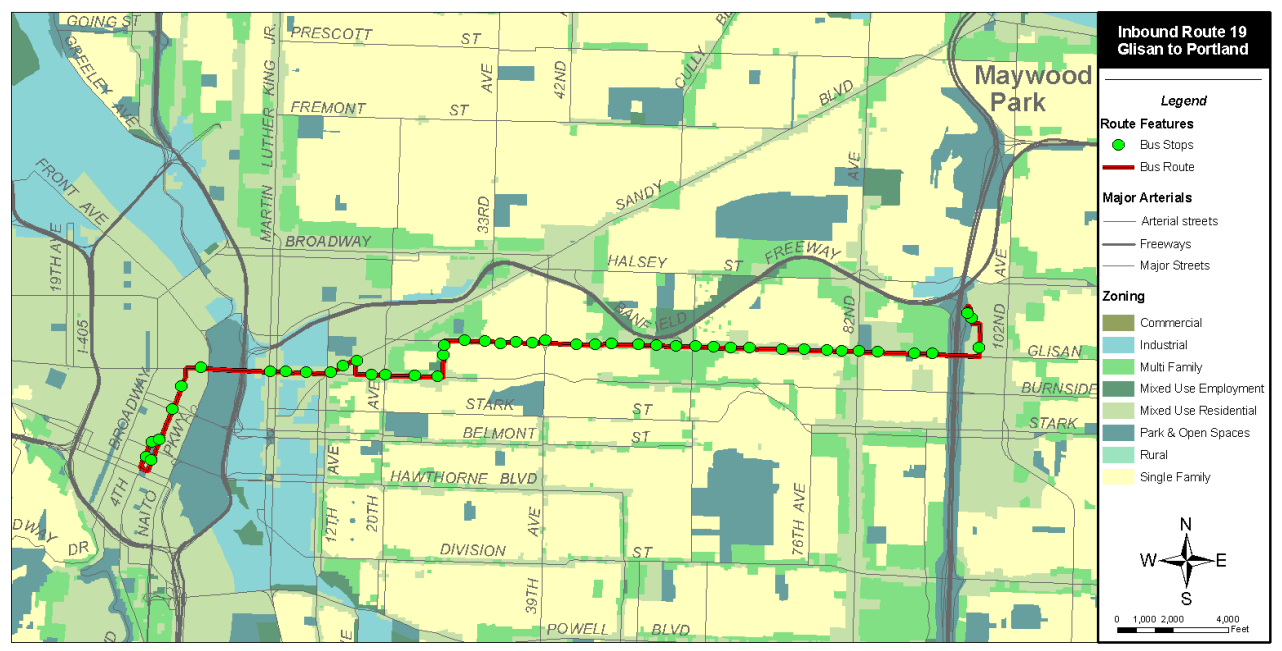

FIGURE 7 Study route map.

With a street grid based on 20 blocks/mile in many Portland neighborhoods (264 feet per block), and an average of $942 \mathrm{ft}$ stop spacing, there is approximately one bus stop every 3.5 blocks along the route.

First, a basic statistical analysis on the current bus stop spacing is shown to characterize the current situation. As mentioned above, the variables including the number of passengers on the bus $N$, the density of origins and destinations $p$, and the lost time due to stopping to serve passengers $\tau$ are analyzed based on the one year's archived data. Figure 8 and Figure 9 show the sequential stop spacing as well as the mean passenger load for the entire year by stop. Over the 46 inbound stops, the mean spacing is 886 feet and the mean load between each stop ranges between 2 and 23 passengers. Accordingly, over the 51 outbound stops, the mean spacing is 891 feet and the mean load by each stop ranges between 3 and 25 
passengers.

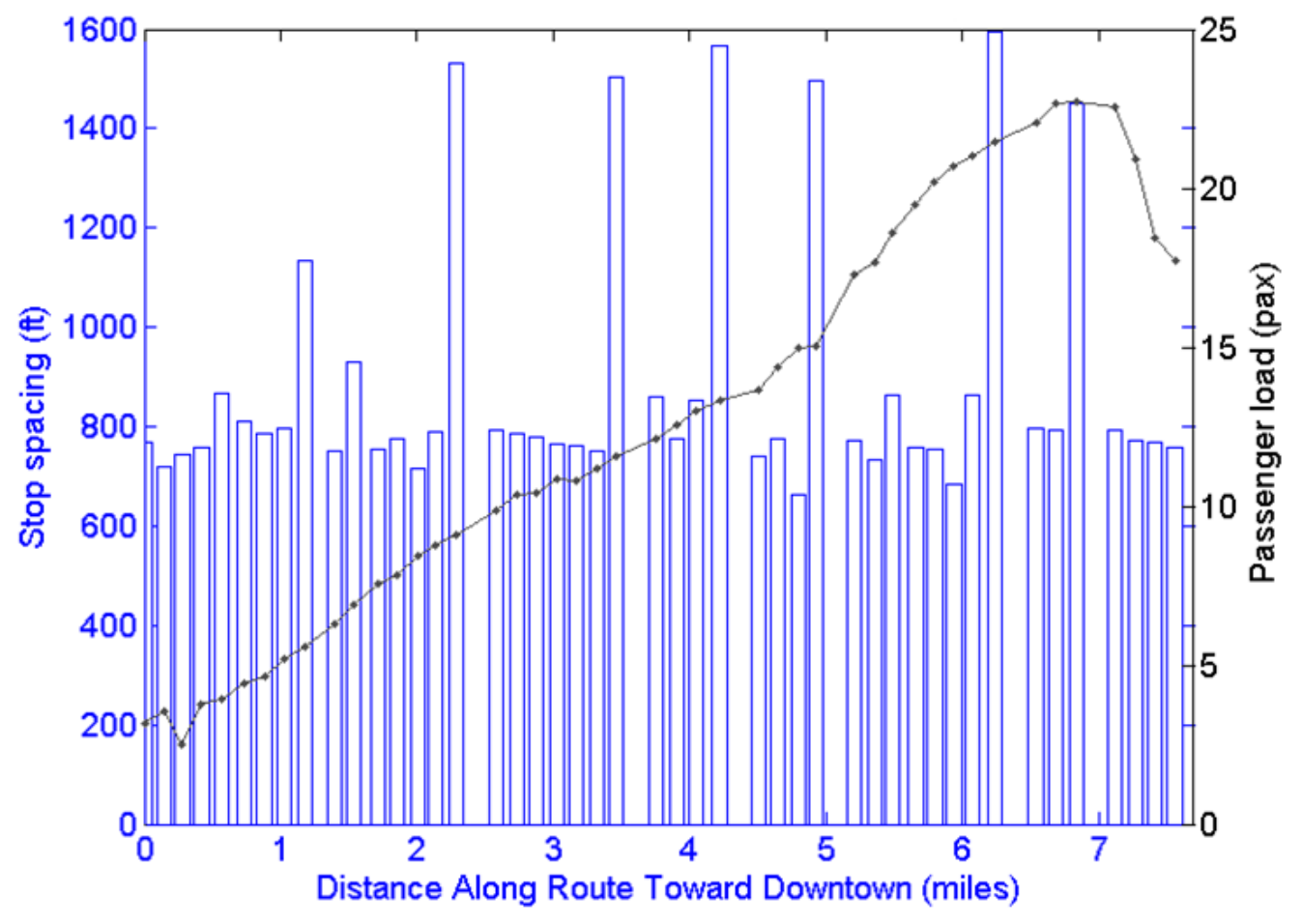

FIGURE 8 Stop spacing distribution, Route 19, Inbound 


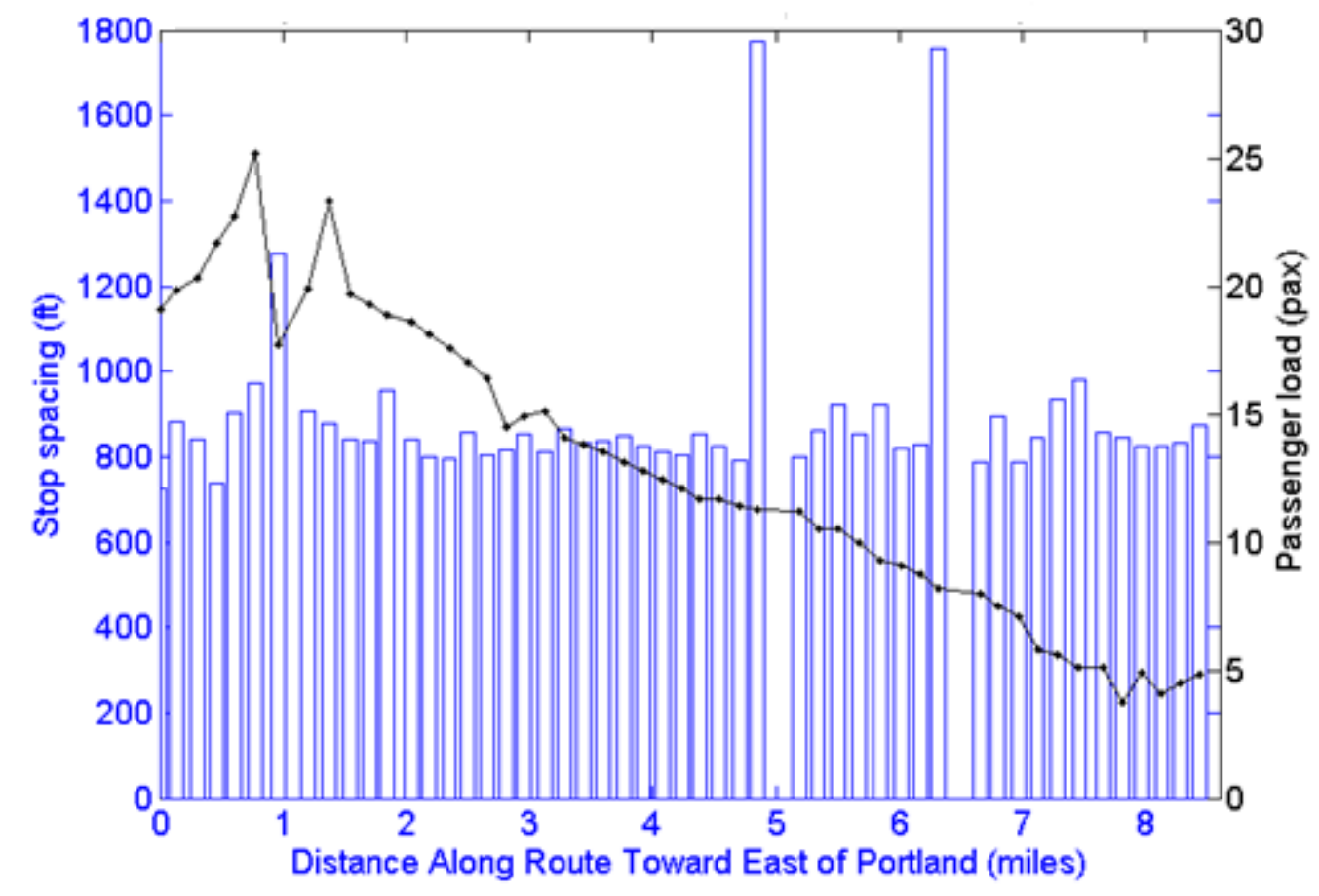

FIGURE 9 Stop spacing distribution, Route 19, Outbound

From the perspective of spacing optimization shown in Figure 1, the current spacing has not reached the minimum user cost and has potential for optimization. At the same time, not surprisingly, the passenger load is increasing as the bus approaches downtown during the AM peak by averaging the whole year's data. Figure 10 shows the results of an analysis testing the statistical significance of the association between stop spacing and passenger load for Route 19.

The derived model represents the relationships between the spacing and related variables. As shown in equation 7, the analytical relationship between spacing and the passenger load is assumed as that the spacing is linear with the 
square root of passengers load. In order to observe the problem of current spacing, the empirical data is analyzed to show whether the current spacing considers passenger activities at the stop level. The relationship is revealed through a significance analysis. If the relationship between current spacing and passenger load is significant, then, it can be confirmed that the current spacing does consider the passenger load and do not need be optimized; adversely, it has potential to optimize. Figure 10 shows the correlation between passenger load and stop spacing, in order to identify whether a change in passenger load is associated with a change in the current spacing. In Figure 10, the $x$-axis shows the square root of the number of passengers on the bus by stop and the $y$-axis shows the corresponding spacing. In order to investigate relationships between these two variables, the technique of correlation is used to test the statistical significance of the association. The regression analysis is also presented as the solid lines in the figure to describe the relationship by means of an equation. The correlation coefficient $\mathrm{R}$ is 0.145 for inbound route and 0.0625 for outbound route, which are all less than 0.273 with 50 degrees of freedom and probability 0.05 in the table of correlation coefficients.

This means that the correlation between these two variables is insignificant; that is, the current spacing does not consider passenger load which is related to in vehicle passengers' value of time. In reality, the more passengers in vehicle, the more valuable for in vehicle passengers travel time, the less frequency the bus stops. The passengers in vehicle experience more frequent stops adding additional travel time which raises the total riding cost. It can be proved that the current stop spacing 
does not consider the user cost and has potentials to be improved and optimized. The candidate stop spacing optimized will be based on the stop level passenger activities.

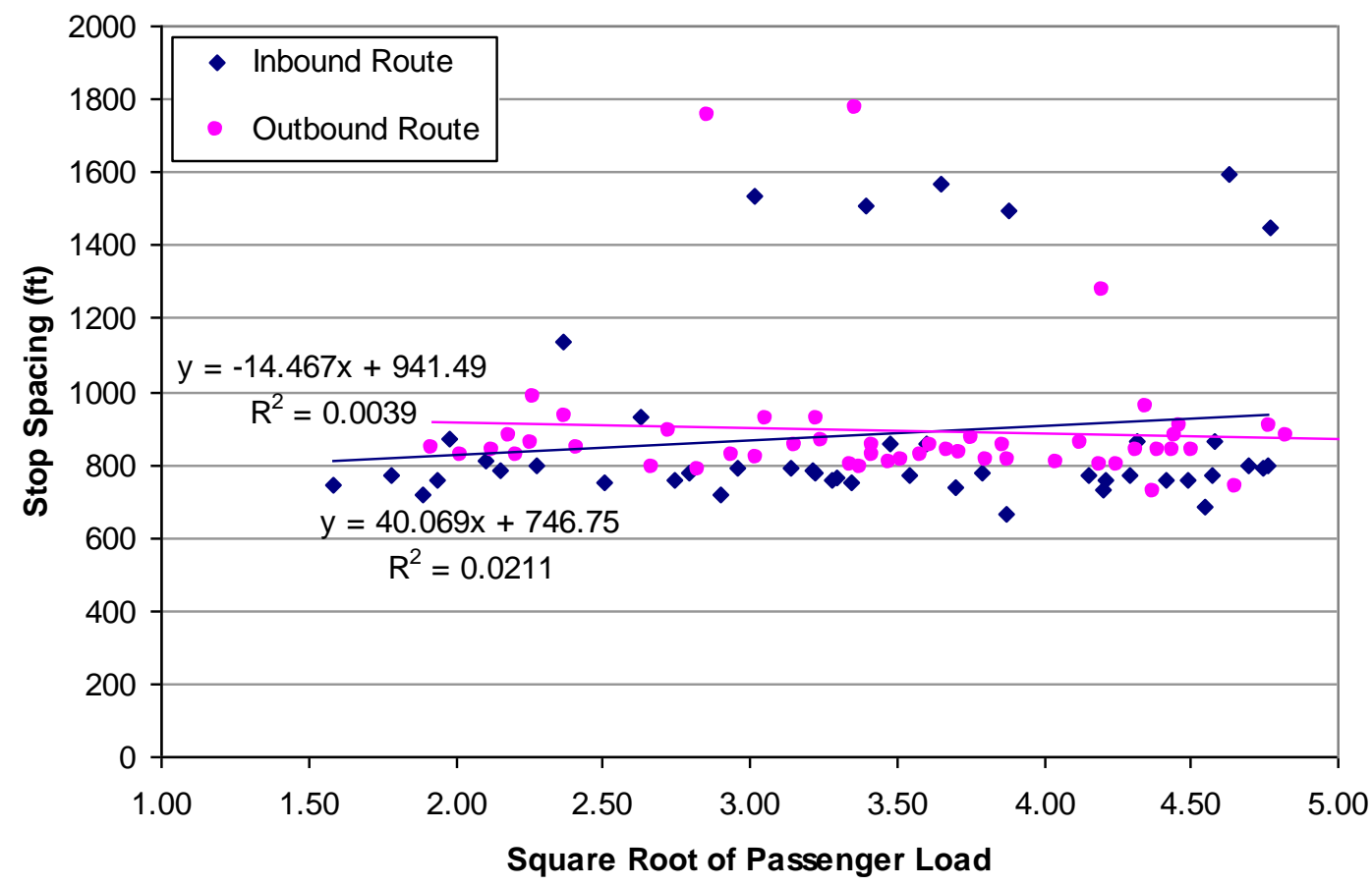

FIGURE 10 Correlation between passenger load and current spacing for inbound Route 19.

\subsection{DAILY ANALYSIS}

The model presented above is applied to a case study on inbound Route 19 for all day analysis. During the construction of the downtown Portland transit mall in 2007, this transit line was rerouted at a few stops for around a half year's time. The analyzed bus route creates a buffer at the beginning and end of the physical route; 
around 1.5 miles of the physical route were excluded in this analysis. The procedure of data cleaning includes:

- Stop ID Filter, to eliminate the unreasonable start and end of routes;

- Travel Velocity Filter, to eliminate routes requiring impossible speeds;

- Passenger Number Outliers Filter, to eliminate unreasonable number of passenger load, as well as boardings and alightings;

- Timestamp Delay Filter, to eliminate the trips with overly long travel time.

After cleaning the data, a total of 17,076 inbound trips from February 20, 2007 to January 5, 2008, over 370 days, were examined. A basic almanac of the Route 19 data is shown in Table 2.

TABLE 2 Basic almanac of the studied inbound Route 19.

\begin{tabular}{r|c}
\hline \multicolumn{1}{c|}{ Content } & Value \\
Direction & all inbound trips \\
Routyzed data & Feb 20, 2007-Jan 5, 2008, 370 days \\
Number of stops & 7.7 miles \\
Current mean spacing & 46 \\
Mean trip time & $886 \mathrm{ft}$ \\
Scheduled trip time & $29.2 \mathrm{~min}$ \\
Number of trips & 27 min \\
20.5 hours of service & 19,344 \\
Mean number of stops per trip & 18 minutes (higher on weekends) \\
Mean weekday headway with 66 trips over & 18.3 \\
Mean boardings and alightings per trip & 33.2 passengers \\
Mean boardings and alightings per mile & 3.6 passengers \\
Mean passengers on bus per stop & 7.9 passengers \\
Mean lost time & 33.6 sec \\
\hline
\end{tabular}




\subsubsection{Passenger Load}

The distribution of the number of passengers on the bus for the entire year every time a bus stopped at each bus stop was analyzed. As shown in the histogram in Figure 11, the $x$-axis is the bin containing the number of passengers and the $y$ axis is the percentage of data falling into the corresponding bin. In order to investigate the population mean and standard deviation of the passenger load with this large set of samples and to eliminate the contribution of unreasonable samples in the data set, the normal distribution fitting is used to analyze the population mean against the sample mean. For example the high percentage of zero values in Figure 11 (a). The white area between milepost 7 to 9 shown in the time space diagram in Figure 11 (b) demonstrates that some stops in the downtown area are not always served during the day in this analysis period - this is the result of construction or closures. The bus line provides service from 5 am to 1 am in the following day.

As shown in the figure (b), few passengers are present on the bus during midnight. It induces zero values in Figure (a). This could also be due to the post processed passenger load, where data are stored at all stops even if the bus does not stop to serve passengers. In order to eliminate the bias from samples, the curve fitting is used to find the population mean. The population mean shows that the average value every time the bus stopped at each bus stop during the entire year was 7.9 passengers with a standard deviation of 2.8 passengers. The maximum 
number of passengers on the bus at each stop was 34 passengers within a 95\% confidence interval.

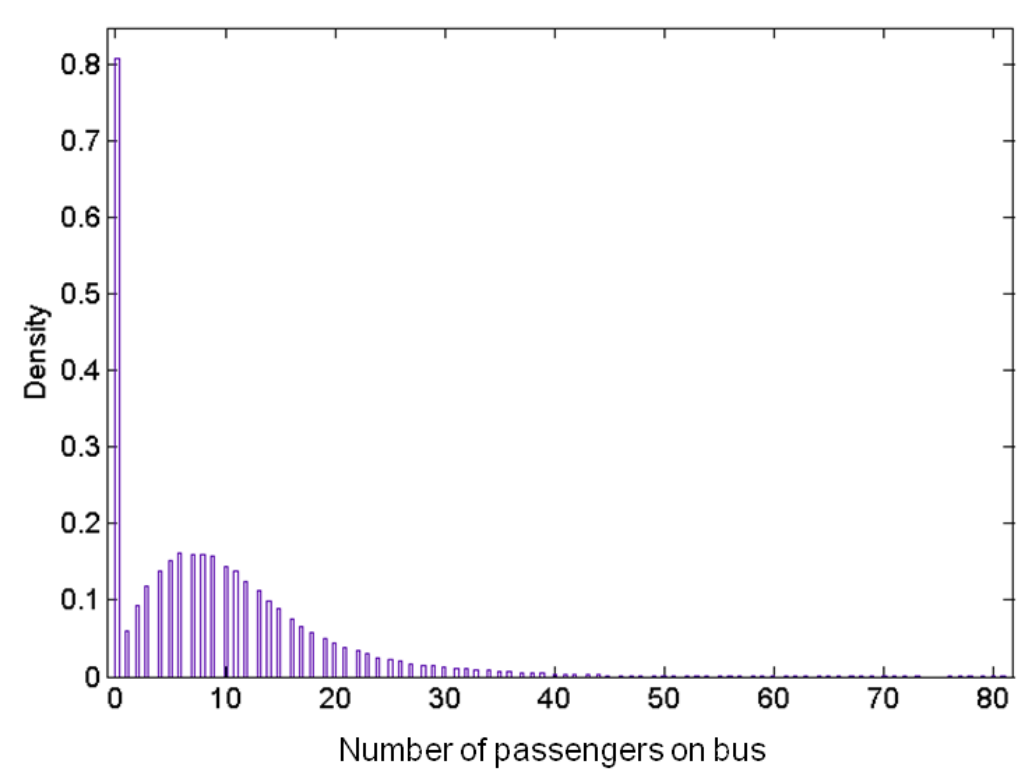

(a) Histogram

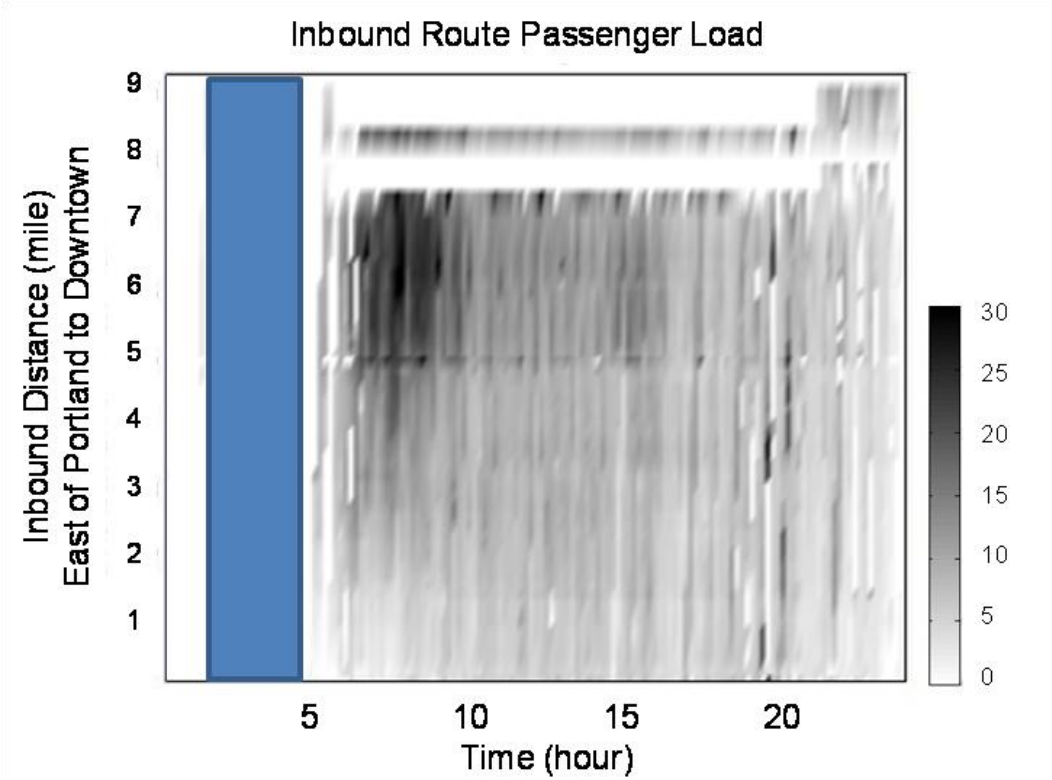

(b) Time space diagram (note: the shade area are not in service from $1 \mathrm{am}$ to $5 \mathrm{am}$ )

FIGURE 11 Distribution of passengers load for all day analysis on inbound Route 19, 2007. 


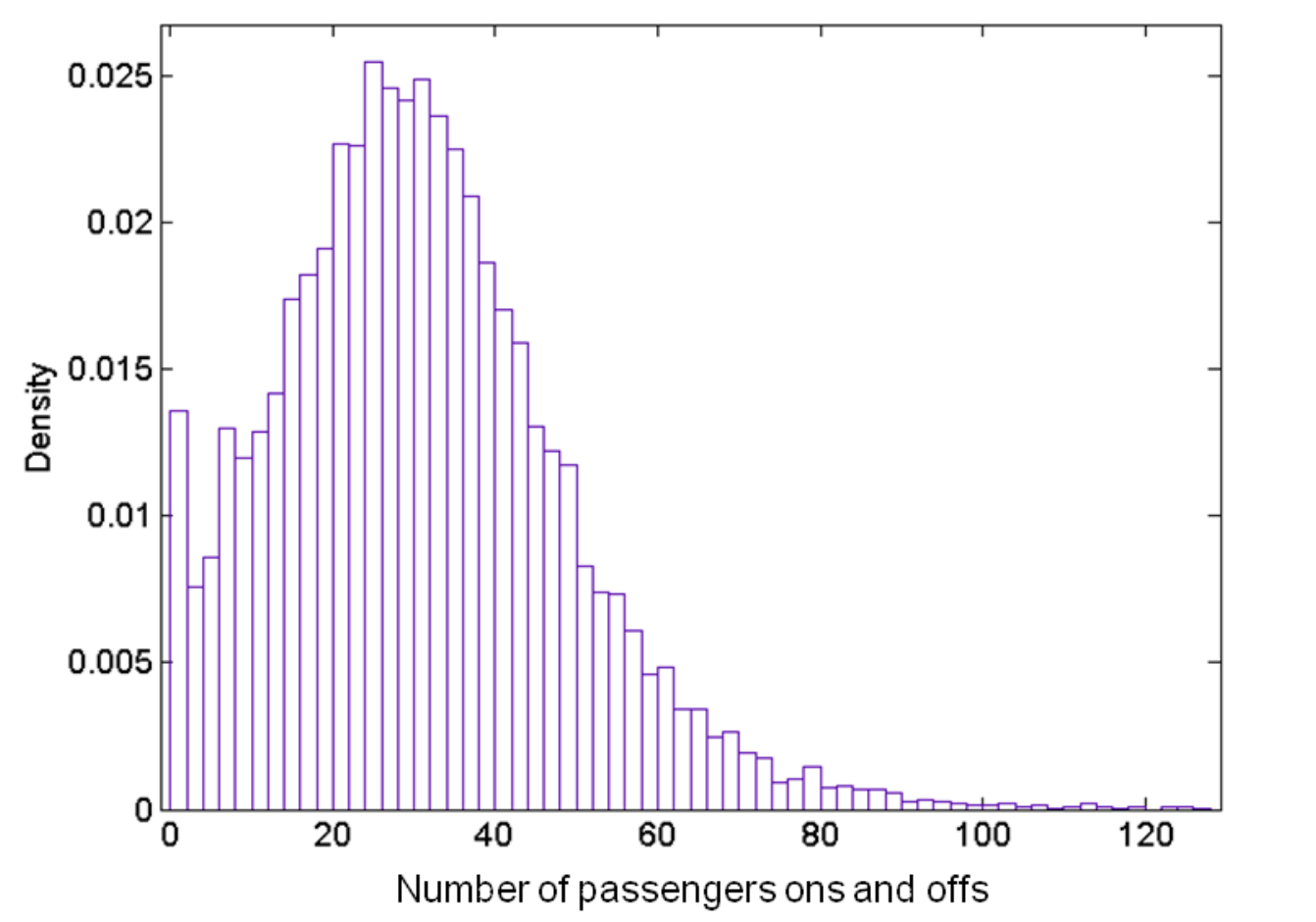

FIGURE 12 Total passenger ons and offs per trip for all day analysis on inbound Route 19, 2007.

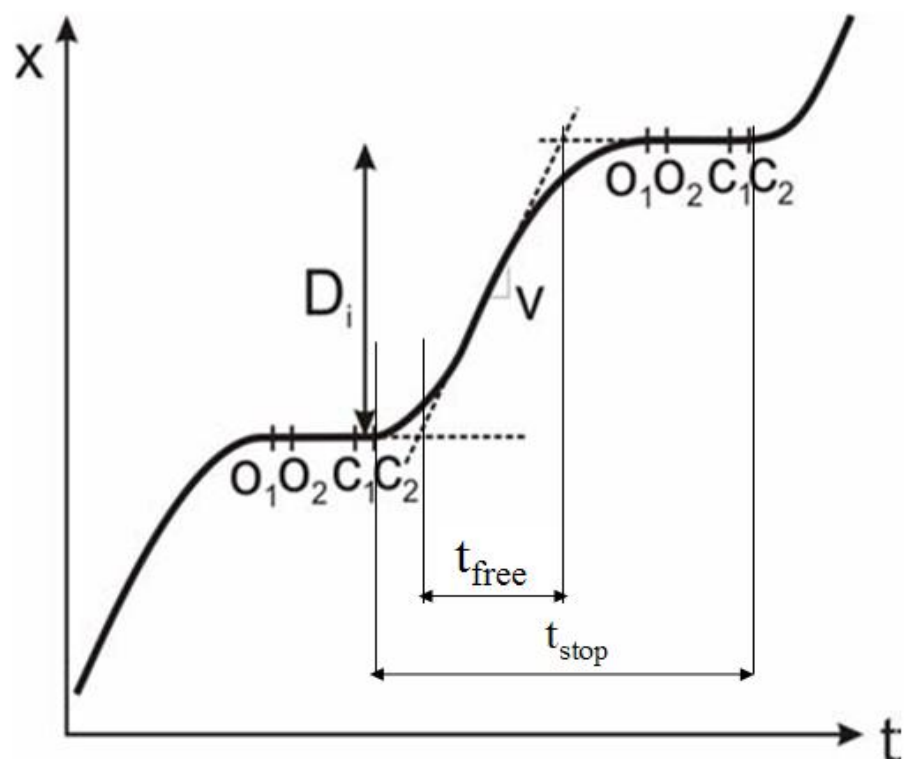

FIGURE 13 Bus trajectory between two stops. 


\subsubsection{Boardings and Alightings}

In order to examine the transit attraction of this route, the distribution of passenger boardings and alightings for each trip was also analyzed to gain a preliminary understanding of the distribution as shown in Figure 12. There are 16,545 trips analyzed in total. The density of origins and destinations, $p$, can be calculated from the archived boardings and alightings in the Bus Dispatching System (BDS) database. A normal curve fitting is used in analysis for comparing the sample mean and population mean to examine the degree of uncertainty for the observed data. The mean of boardings and alightings was 33.2 persons per trip, and thus the passenger density $p$ was 3.6 persons/mile.

\subsubsection{Stopping Time}

The lost time due to stopping to serve passengers in the stop spacing model, $\tau$, can be obtained from the value of mean delay due to stopping including the dwell time for serving passenger boarding and alighting, the time during which the door is opened and closed, and the deceleration and acceleration time. This is illustrated by a hypothetical time-space trajectory shown in Figure 13. Consider a hypothetical trajectory of a vehicle traveling between two stops of which the distance is $D_{\mathrm{i}}$ as shown in Figure 13. The $x$-axis in the figure is time and the $y$-axis is distance. There are certain points along this trajectory that an observer in the vehicle or at a 
boarding point can measure quite accurately, namely the time (and location) when the door of the vehicle first starts to open $o_{1}$, when it is fully open $o_{2}$, when it first starts to close $c_{1}$, and when fully closed, $c_{2}$. The delay due to stopping is the free flow trip time subtracted from the stop time, that is, $t_{\text {stop }}-t_{\text {free }}$ assuming that the acceleration time is equal to the deceleration time. Using the recorded arrival time, departure time, maximum speed and stop mileage data, the mean delay due to stopping $(\tau)$ was calculated as $33.6 \mathrm{~s}$. The number of passengers on the bus, $N$, also can be directly obtained from the passenger load record in the database.

\subsubsection{Optimized Stop Spacing}

Having calculated the value of variables including density of origins and destinations $p$, time lost in stopping to serve passengers $\tau$, and number of passengers on the bus $N$, the optimal bus stop spacing can be obtained from the model using Equation 7. The results are shown in Figure 14. Solid lines show the optimized stop spacing with different values for passenger boardings and alightings, indicating the accessibility of bus stops. The $x$-axis shows the range of passenger load indicating the riding cost. With the distribution of number of passengers on the bus along the route, the optimized spacing can be obtained by intersecting the passenger load. For Route 19 given the mean load of 7.9 passengers and a mean of 33.2 passenger movements, an optimal stop spacing of 1,222 ft can be read from Figure 13. A step function indicating 20 blocks/mile is added to the figure to illustrate that actual stops would be placed according to the actual street grid, 
resulting in a sense of how many blocks are appropriate for the optimized spacing. From this analytical result of the case study, the existing spacing policy is found to provide more accessibility with a high access cost; The existing spacing ignores the value of in vehicle time for those transit riders who expect a short trip time. As the problem arise over time, the spacing policy can be re-examined by the methods defined in this paper. Any decision-making process for bus stop consolidation and removal can be made over the entire route or for particular segments using this tool.

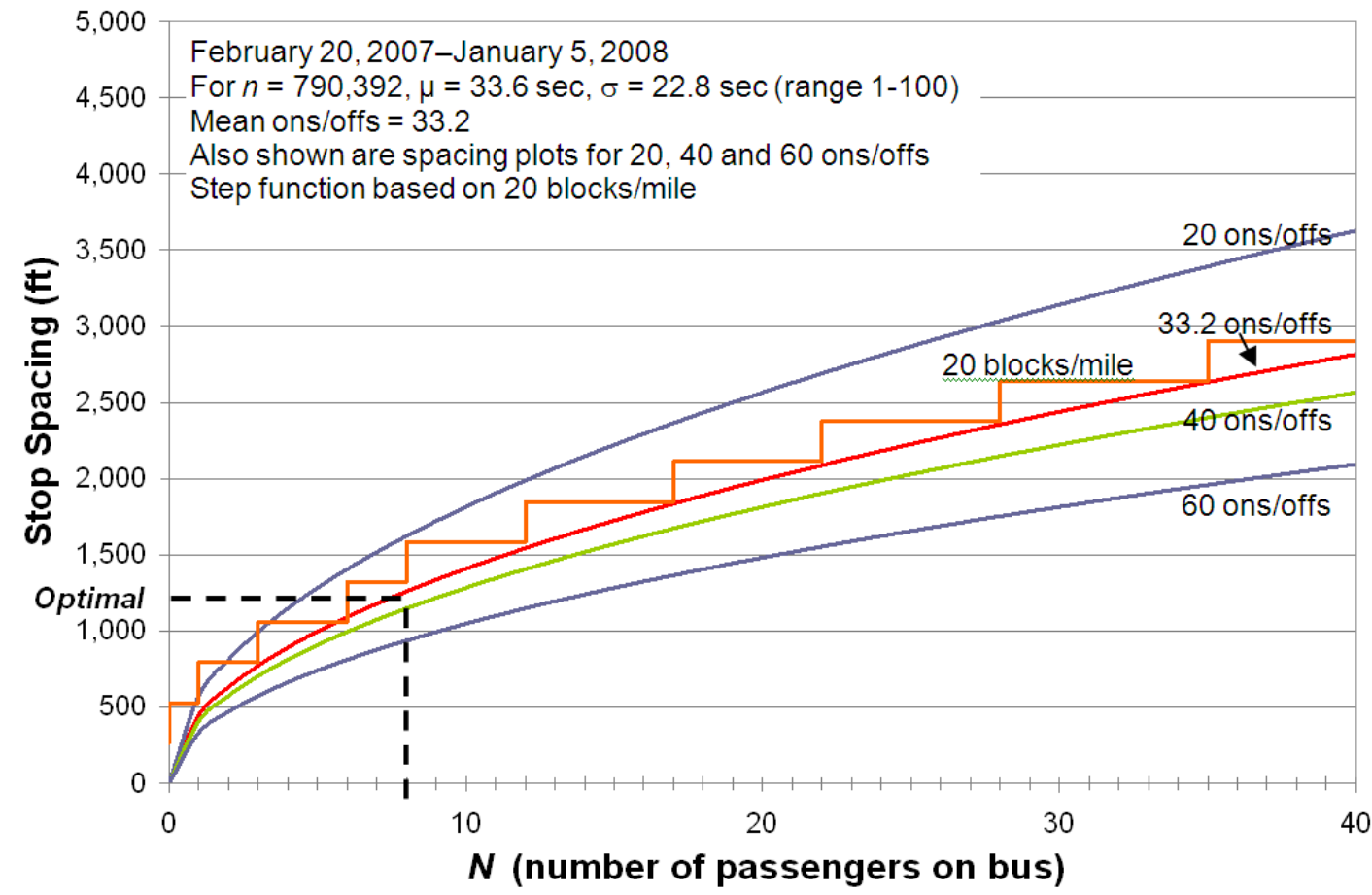

FIGURE 14 Optimized bus stop spacing for inbound Route 19 based on all day analysis.

The previous stated spacing calculation procedure presents a simply method which is applicable for practical use. The calculated stop spacing $1222 \mathrm{ft}$ is based on the 
assumption that the value of in vehicle riding time is four times the value of access time. In the next section, the sensitivity analysis will be performed to shown how the value of time affects the optimal spacing and how the user cost varies with the value of time. The values are also compared between before and after optimization as described in the next section.

\subsubsection{Sensitivity Analysis}

Optimizing bus stop spacing can help agencies reduce their fleet sizes, improve trip times, and increase service reliability $(8,17,18,23)$. The application of the optimal stop spacing model has resulted in a possibility of removing or consolidating twelve bus stops for Route 19, considering the desire to minimize user cost. It is now possible to examine the impact of the input parameters on the cost of providing transit service. In general, from TriMet's perspective, consolidating stops is one strategy that can be used to reduce operating cost. In order to identify the time saved due to bus stop consolidation, a basic trip time model (19) developed in previous research was applied using one year's BDS data. Based on the trip time model, with the average Route 19 trip time of $29.2 \mathrm{~min}$, the time saved solely due to acceleration and deceleration would be $17 \mathrm{sec}$ per stop. With this savings, the trip time of each inbound trip for this route would be reduced by $3.4 \mathrm{~min}$ to 25.8 min after 12 stops are removed or consolidated. For the 370 days of bus runs analyzed, a total of 17,076 inbound trips, the time saved would be 977 hours during the year. Using a basic assumption of $\$ 60 / \mathrm{hr}$ operating cost, about $\$ 60,000$ could 
be saved by TriMet due to stop consolidation for inbound Route 19. It is possible to assess a potential system wide operations cost savings for the entire year using this approach. These cost savings are hypothetical and might not be translatable to real savings, since, for example, headways may be set by policy.

The time savings could be used improve service by adding more trips. Given that TriMet provides 66 scheduled inbound trips per weekday on Route 19, the total savings due to consolidation could be up to 3.7 hours of service time per day. Without performing a complete operational analysis, this could allow for approximately 7.6 additional trips per weekday on inbound Route 19. This would result in improved headways, whereby the mean weekday headway would drop from $18.0 \mathrm{~min}$ to $16.1 \mathrm{~min}$.

Increased stop spacing after optimization would need to be balanced carefully against the additional walking/access distance for some passengers and the negative prospect of removing bus stops. Any stop consolidation decision would need to take into account existing passenger activity and land use patterns. The benefits and costs are also analyzed from the user perspective. As illustrated in the stop spacing model in the previous section, the optimized spacing is related to the ratio of the value of access time to that of riding time. Table 3 contains a sensitivity analysis on this point.

Table 3 shows the relationship between the ratio of assumed access time to riding time and the corresponding user cost per unit length. As shown, with the 
optimized spacing, the total user cost would be reduced at the expense of increased access cost. Some researchers debate that the value of access cost is weighted higher than riding cost. At this point, the spacing model included a ratio of value of access time to value of riding time as a factor to illustrate the difference between access cost and riding cost. Even though the calculated access cost is higher than the current condition, the value still appears to be reasonable after optimization.

TABLE 3 Sensitivity analysis for the optimized spacing based on all day analysis on inbound Route 19.

\begin{tabular}{r|r|ccc}
\hline & $\gamma_{r} / \gamma_{a}$ & $1 / 2$ & $1 / 3$ & $1 / 4$ \\
& Optimized Spacing (ft) & 1728 & 1411 & 1222 \\
\hline \multirow{4}{*}{ Access Cost } & Value of access time $(\$ / \mathrm{hr})$ & $\$ 16 / \mathrm{hr}$ & $\$ 18 / \mathrm{hr}$ & $\$ 20 / \mathrm{hr}$ \\
& Before optimized (passenger \$/unit length) & $\$ 0.64$ & $\$ 0.72$ & $\$ 0.80$ \\
& After optimized (passenger \$/unit length) & $\$ 1.18$ & $\$ 1.08$ & $\$ 1.04$ \\
& Change (passenger \$/unit length) & +0.54 & +0.36 & +0.24 \\
\hline \multirow{3}{*}{ Riding Cost } & Value of riding time (\$/hr) & $\$ 8 / \mathrm{hr}$ & $\$ 6 / \mathrm{hr}$ & $\$ 5 / \mathrm{hr}$ \\
& Before optimized (passenger \$/unit length) & $\$ 2.30$ & $\$ 1.72$ & $\$ 1.44$ \\
& After optimized (passenger \$/unit length) & $\$ 1.83$ & $\$ 1.50$ & $\$ 1.32$ \\
& Change (passenger \$/unit length) & -0.47 & -0.22 & -0.12 \\
\hline
\end{tabular}

In order to identify consolidated or removable stops along inbound Route 19, the peak hour transit demand must be analyzed in time and space. As the bus approaches downtown, it is obvious that the downtown area has a higher passenger load during the morning peak hours. In view of minimizing user cost, inbound Route 19 should have larger stop spacing near the downtown area. The next step in this research is to analyze peak hour transit demand. 


\subsection{PEAK HOUR ANALYSIS}

As a transit commuter line between downtown and residential areas to the east, the ridership on Route 19 exhibits inbound peak demand in the morning and outbound peak demand in the evening. Therefore, the transit performance of this route during the weekday morning peak from 6:00 to 9:00 and the evening peak from 15:00 to 18:00 as defined by TriMet is also analyzed in order to explore the potential of optimizing stop spacing. A basic almanac of the inbound and outbound Route 19 peak hour data is shown in Table 4. All the following scenarios are peak hour demand analysis.

TABLE 4 Route 19 peak hour data almanac for both inbound and outbound Route 19.

\begin{tabular}{r|c|c}
\hline & AM Peak Inbound Trips & PM Peak Outbound Trips \\
\hline Route Length & 7.7 miles & $8.6 \mathrm{miles}$ \\
No. of Scheduled Bus Stops & 46 bus stops & $51 \mathrm{bus} \mathrm{stops}$ \\
Scheduled Headway & $12 \mathrm{~min}$ & $12 \mathrm{~min}$ \\
Current Mean Spacing & $886 \mathrm{ft}$ & $891 \mathrm{ft}$ \\
Number of Trips & $3,658 \mathrm{trips}$ & $3,908 \mathrm{trips}$ \\
Mean Trip Time & $32.6 \mathrm{~min}$ & $41.2 \mathrm{~min}$ \\
Mean No. of Stops Per Trip & 24.4 & 20.7 \\
Mean Ons and Offs Per Trip & 40.0 passengers & 47.7 passengers \\
Ons and Offs Per Mile & 5.2 passengers & 5.0 passengers \\
Mean Passenger Load Per Stop & 37.0 passengers & 12.1 passengers \\
Mean Stopping Time & 37.0 sec & $35.9 \mathrm{sec}$ \\
\hline
\end{tabular}

\subsubsection{Passenger Load}

In order to explore the passenger riding cost function, the distribution of the number of passengers on the bus every time a bus stopped at each bus stop was analyzed for the route during peak hours. The average number of passengers on the 
bus at each stop during the morning peak hours for the inbound route was 12.8 passengers with a standard deviation of 11.9 passengers; the maximum number of passengers on the bus at each stop was 36 passengers within a 95\% confidence interval. During the evening peak hours for the outbound route, the average number of passengers on the bus at each stop was 12.1 passengers with a standard deviation of 11.6 passengers; the maximum number of passengers on the bus at each stop was 35 passengers within a $95 \%$ confidence interval.

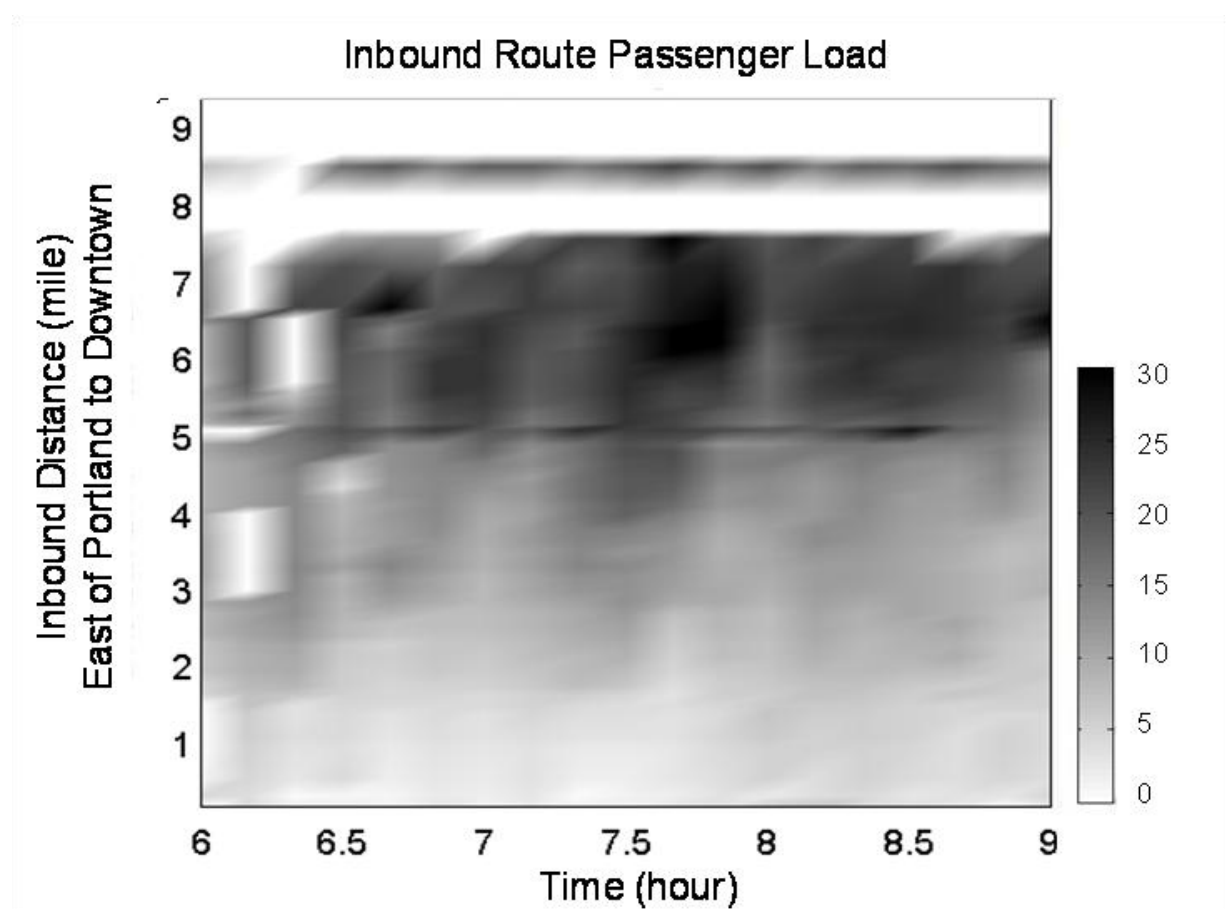

FIGURE 15 Distribution of passenger load for inbound Route 19. 


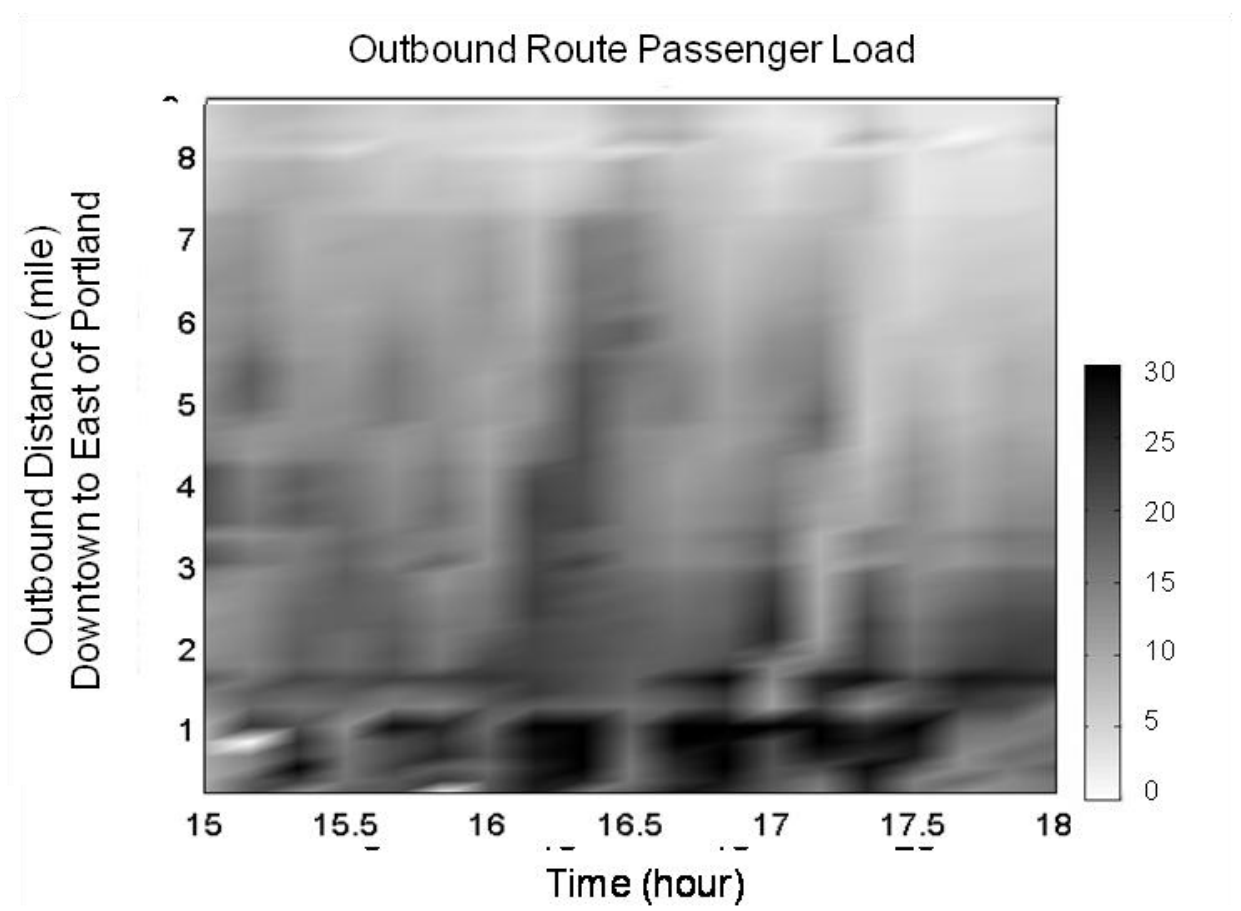

FIGURE 16 Distribution of passenger load outbound 19.

Additionally, passenger load is analyzed in the time-space dimension. As shown in Figure 15 and Figure 16, the $x$-axis is time of day and the $y$-axis shows distance from the origin of every trip. Inbound trips indicate downtown Portland attractions and outbound trips indicate downtown transit trips productions along this route. It is valuable to see the transit patterns by time of day for attractions and productions. From Figure 15 and Figure 16, the high passenger load for inbound and outbound trips are all located at the downtown route segment; however, the peak demands by time of day exhibit different patterns. The inbound route exhibits higher demand during morning peak hours around 6:00 to 9:00; conversely, a similar pattern occurs during the evening peak hours from 15:00 to 
18:00 for the outbound route. This can be used as the basis for an optimal bus stop location procedure in order to satisfy high passenger demand.

\subsubsection{Boardings and Alightings}

For this case study, more than 1,800,000 passenger movements were analyzed to consider the passenger demand for each bus stop along both inbound and outbound trips during peak hours. The distribution of passenger boardings and alightings for each trip were also analyzed to gain a better understanding the distribution. The density of origins and destinations, $p$, can be calculated from the archived boardings and alightings in the BDS database. In Figure 17, it is shown that the mean number of boardings and alightings was 40.0 persons per inbound trip during AM peak hours (with a standard deviation of 21.2 persons) and 47.7 persons per outbound trip during PM peak hours (with a standard deviation of 28.7 persons). Thus the passenger density, $p$, was 5.2 persons/mile for the inbound route and 5.5 persons/mile for the outbound route.

Additionally, using the passenger ons and bus arrival time record at each stop for each trip, the pattern of passenger arrivals at a bus stop (which is commonly assumed as Poisson distribution) could be verified. The passenger boardings at a single stop (stop ID 2110) on outbound Route 19 was tested by aggregating hourly passenger ons at this stop from one year's worth of data shown in Figure 18. With a Poisson distribution fit, the mean arrival rate is 3.4 passengers per hour with a standard deviation of 3.4 passengers per hour. By comparing and fitting all possible 
distributions, the most closely fitted distribution is the negative binomial distribution. The Poisson distribution was also tested with a less strong fit than the negative binomial distribution by comparing the maximum log likelihood. Even though the result shown here is different from was expected, further analysis could be performed using the BDS data.

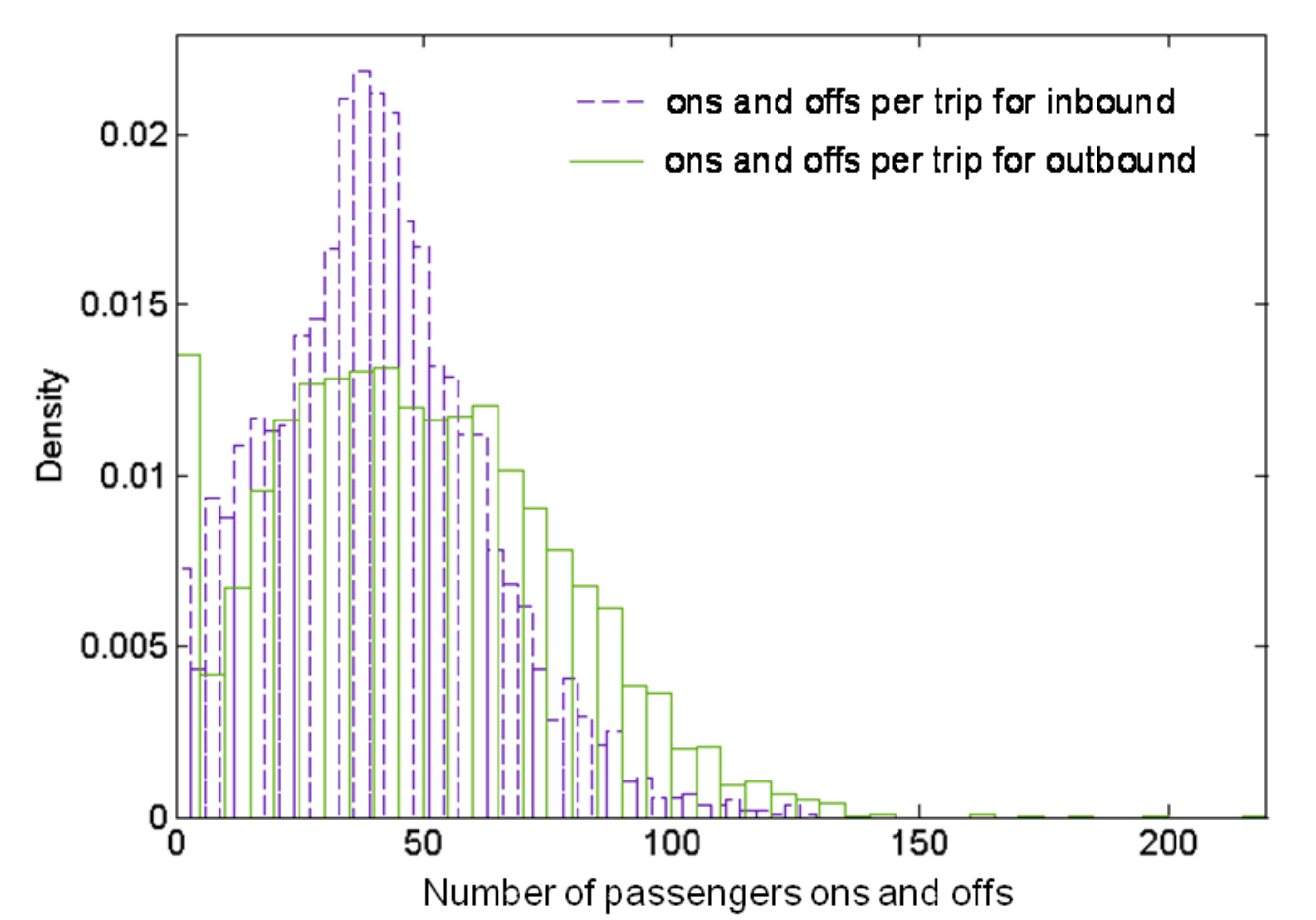

FIGURE 17 Passenger ons and offs per trip for peak hour analysis on both inbound and outbound Route 19 in the year 2007. 


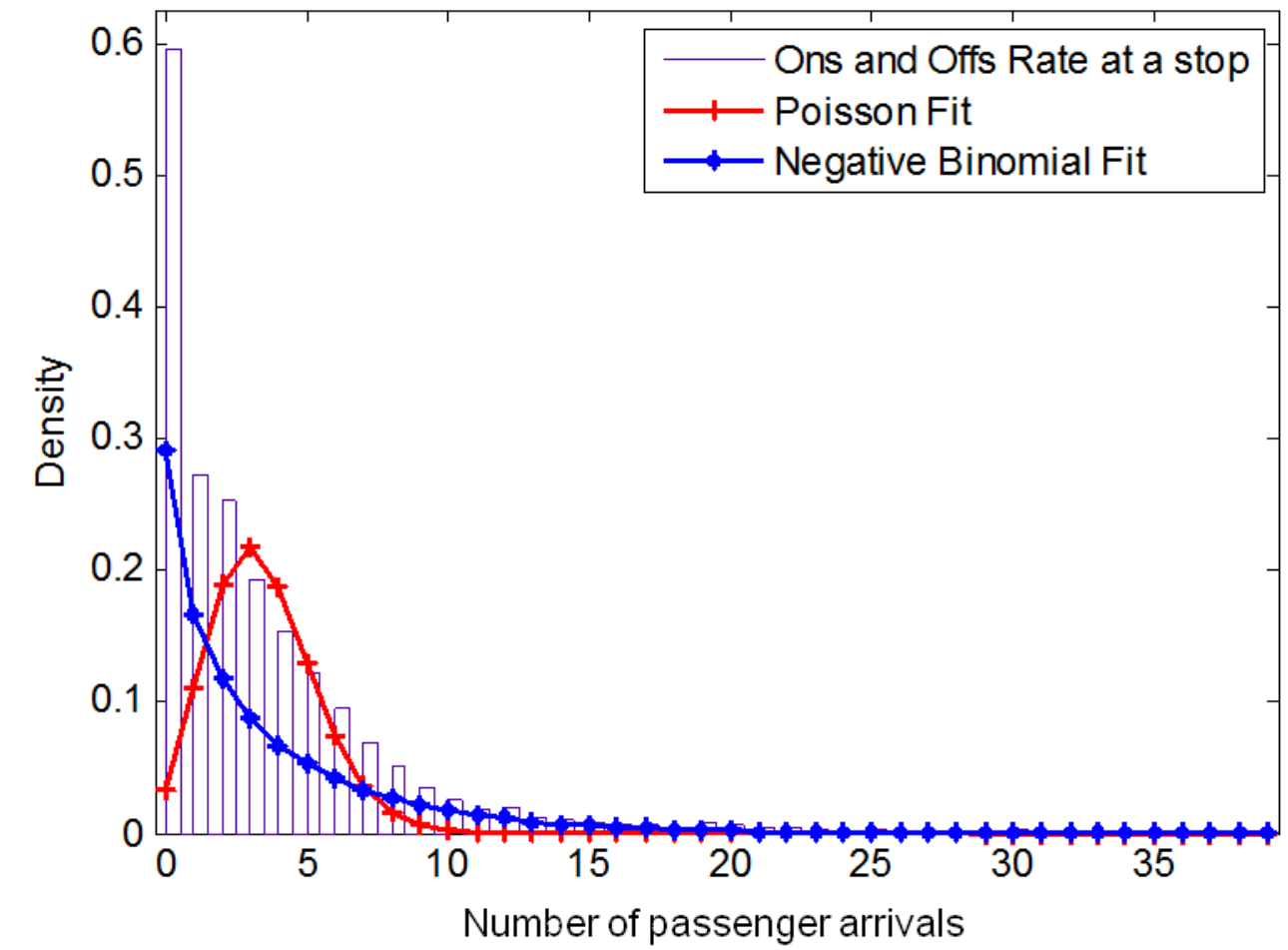

FIGURE 18 Passenger arrival rate for peak hour analysis on stop ID 2110 along Route 19 in the year 2007.

\subsubsection{Stopping Time}

Using the recorded arrival time, departure time, maximum speed and stop mileage data shown in Figure 13, the mean delay due to stopping, $\tau$, were calculated as $37.0 \mathrm{sec}$ for inbound stops and $35.9 \mathrm{sec}$ for outbound stops. The number of passengers on the bus $N$ also can be directly obtained from the passenger load record in the database. 


\subsubsection{Optimized Stop Spacing}

In order to satisfy maximum transit demand, peak period demand is used as the basis of optimal spacing procedure, that is, the morning peak demand for the inbound route and the evening peak demand for the outbound route. Table 5 summarizes the variables used in optimizing the stop spacing for the inbound and outbound routes calculated from the one year's worth of data.

TABLE 5 Values of variables in spacing optimization model.

\begin{tabular}{|c|c|c|c|c|c|c|}
\hline & \multicolumn{2}{|c|}{ Passenger Load } & \multicolumn{2}{|c|}{ Boardings \& Alightings } & \multicolumn{2}{|c|}{ Lost Time } \\
\hline & Mean & Max. & Per trip & Per mile & Mean & St.dev. \\
\hline Inbound (AM) & 12.8 persons & 37 persons & 40.0 persons & 5.2 persons & $37.0 \mathrm{sec}$ & $22.8 \mathrm{sec}$ \\
\hline Outbound (PM) & 12.1 persons & 35.3 persons & 47.7 persons & 5.5 persons & $35.9 \mathrm{sec}$ & $22.0 \mathrm{sec}$ \\
\hline
\end{tabular}

Knowing the values of variables shown in Table 5, the optimal bus stop spacing can be obtained from the model using Equation 7. The results are shown in Figure 19. Solid lines show the optimized stop spacing with values for passenger boardings and alightings indicating the accessibility of bus stops. The $x$-axis shows the range of passenger load indicating the riding cost. With the distribution of number of passengers on the bus along the route, the optimized spacing can be obtained by intersecting the passenger load. For inbound Route 19 given the mean load of 12.8 passengers and a mean of 40.0 trip passenger movements, an optimal stop spacing of 1,388 ft can be read from Figure 20; similarly, 1,286 ft optimal spacing for outbound route. These are compared with a value of $1,222 \mathrm{ft}$ obtained 
from the previous analysis of all day. A step function indicating 20 blocks/mile is added to the figure to illustrate that actual stops would be placed according to the actual street grid, resulting in a sense of how many blocks are appropriate for the optimized spacing. It illustrates the fact that the optimal bus stop locations would be about every 4 blocks for both inbound and outbound routes. Any decisionmaking process for bus stop consolidation and removal can be made over the entire route or for particular segments using this tool.

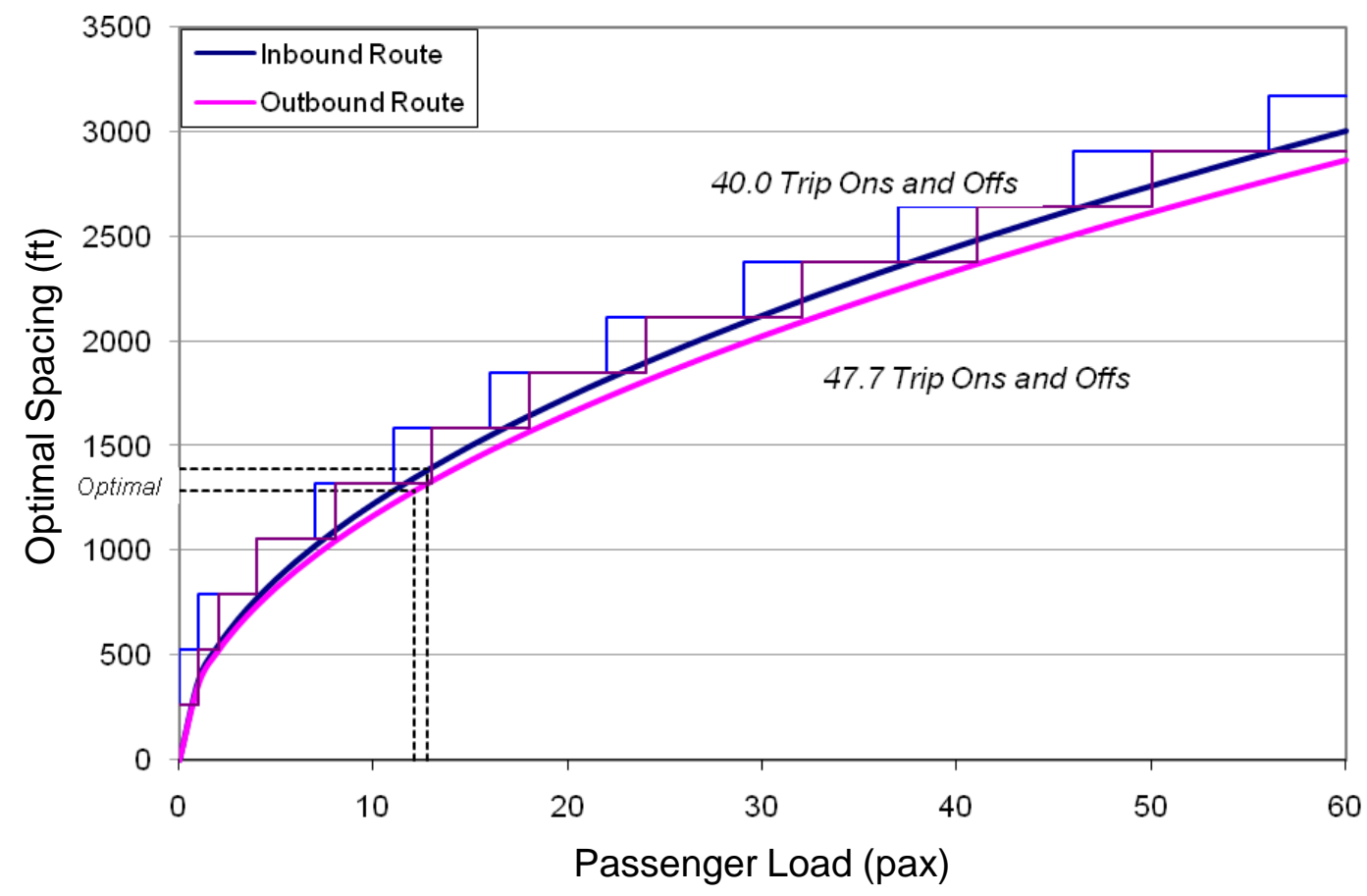

\section{FIGURE 19 Optimized bus stop spacing for Route 19 based on peak hour analysis on both inbound and outbound routes.}

As stated above, this tool can be used to develop guidelines of bus stop spacing policy with this simple optimization model. In practical application, it can be used as the first step for the preliminary planning of bus stops. It provides a 
reference figure that shows how much spacing or how many blocks between bus stops is appropriate for a route. After a detailed temporal analysis for the studied route is performed, a spatial analysis is also needed. Spatial analysis is performed by deviding the studied route into small segments with similar passenger activity patterns as given by the spatial passenger distributions along the route shown in Figure 20. Then, the optimal stop location can be intercepted into this route. The spatial result is shown as bus stop consolidation as stated below. Lastly, it should be noted that the details including geometry, land use, customer needs and so on can be considered to add or remove a bus stop by decision makers.

\subsection{BUS STOP CONSOLIDATION}

In previous two sections, the daily analysis and peak hour analysis were presented to show the difference of optimized spacing due to different demand patterns. The results are summarized in Table 6.

\section{TABLE 6 Values of optimized spacing summary.}

\begin{tabular}{l|c|cc}
\hline & Daily Analysis & \multicolumn{2}{|c}{ Peak Hour Analysis } \\
& Inbound & Inbound & Outbound \\
\hline Optimized Spacing & $1,222 \mathrm{ft}$ & $1,388 \mathrm{ft}$ & $1,286 \mathrm{ft}$ \\
\hline
\end{tabular}

With the goal of identifying consolidated or removable stops along inbound Route 19, the distribution of the passenger load in the time-space plane is diagnosed as shown in Figure 15 and Figure 16. However, passenger ons and offs 
along the route are closely uniformly distributed. Considering the access cost and riding cost, the spacing should favor passengers' riding cost who expected stopping only at their stops. Theoretically, as the bus approaches downtown where it has a higher passenger load, the larger spacing is preferred. Then, in view of minimizing user cost, Route 19 should have larger stop spacing closer to the downtown area. Similarly, for outbound route, there is a high demand in downtown area too. As the bus leaves the downtown areas, the lower passenger load, the shorter spacing is preferred.

Comparing the previous results of the daily analysis and peak hour analysis, the difference of the optimal spacing value is significant. To further examine the transit demand patterns in time of day, the off peak hour transit pattern is compared as shown in Figure 20. The distribution of passenger load and the boardings and alightings in distance are displayed in the reason that the former one is related to the riding and stopping cost, and the latter one indicates access cost. During peak hours, the number of passenger ons and offs distributes evenly over the distance traveled, except for the terminal locations; however, the distribution of passenger load over distance has an obvious trend that there are more number of passengers in vehicle where approaching downtown area for both inbound and outbound routes. Comparing to the off peak hours, the passenger load does not have an obvious difference in distance during peak hours. At the same time, the passenger load during off peak hours is smaller than peak hour. In order to satisfy the highest transit demand in a day, the peak hour demand need be considered specifically 
when doing bus stop consolidation. The peak hour demand is chosen as the reference for the consolidation scheme. Figure 20 illustrates the optimal bus stop locations by focusing just on peak periods for weekdays, dividing the route into specific regimes according to land use patterns and passenger load information. The determination of bus stop consolidation is explained in Table 7. The optimized stop spacing is calculated at stop level, and then by comparing the current spacing and optimized spacing, the bus stop is considered to be consolidated if it is within the optimized spacing. The result shows that in downtown area, every two stops are considered to be consolidated to one stop. In practice, this result is coincidentally similar to the deployment of bus stops before and after the transit mall built. In reality, in the year 2007, which is the data used in this thesis, the downtown Portland was under construction on the transit mall, the bus route was moved to parallel streets. The bus stops were closed deployed that around every two blocks a bus stop and the buses frequently stops in downtown area. With a stop level analysis provided in this session, the bus stops are considered to be consolidated that every two existing stops consolidated to a bus stop in downtown area in the reason of a high passenger load. In reality, the stops are consolidated in this way in downtown Portland after the transit mall built. The transit mall provides a better service for residents. 
TABLE 7 Bus stop consolidation example on first a few stops on outbound Route 19.

\begin{tabular}{c|ccccccc}
\hline Stop ID & $\begin{array}{c}\text { current } \\
\text { spacing }\end{array}$ & $\begin{array}{c}\text { Avg. } \\
\text { Stop Load }\end{array}$ & $\begin{array}{c}\text { Avg. } \\
\text { On\&soffs }\end{array}$ & $\begin{array}{c}\text { Opt. } \\
\text { spacing }\end{array}$ & $\begin{array}{c}\text { Consoli } \\
\text { dated } \\
\text { spacing }\end{array}$ & $\begin{array}{c}\text { Opt. } \\
\text { mileage }\end{array}$ & $\begin{array}{c}\text { Actual. } \\
\text { mileage }\end{array}$ \\
\hline 7767 & 727 & 19.1 & 1.6 & 1672 & & 44917 & 45431 \\
7788 & 880 & 19.8 & 4.2 & 1699 & 1644 & 44917 & 44704 \\
7806 & 839 & 20.3 & 7.4 & 1721 & & 43273 & 43824 \\
7746 & 738 & 21.7 & 3.4 & 177 & 1722 & 43273 & 42985 \\
7796 & 901 & 22.7 & 2.1 & 1822 & & 41551 & 42247 \\
772 & 973 & 25.2 & 3.0 & 1919 & 1857 & 41551 & 41346 \\
12773 & 1274 & 17.7 & 4.2 & 1606 & & 39694 & 40373 \\
9526 & 906 & 19.9 & 3.4 & 1706 & 1651 & 39694 & 39099 \\
\hline
\end{tabular}

Considering solely the user cost, a hypothetical/conceptual stop consolidation and removal plan can now be produced. It should be noted and emphasized that any real stop consolidation program should involve the many stakeholders along a given route, including the bus operators and residents. The theoretical stop location is carefully chosen by comparing the stop location with current stop spacing and optimal stop spacing. The optimal spacing is calculated at each stop, and then, by comparing adjacent stop location, if the adjacent stop is within the optimal spacing, it is considered to be consolidated. The optimal stop locations are intersected along the bus line considering the stop level passenger activities. The before and after optimized stop locations are shown in Figure 21. The figure shows that the optimal stop spacing should be approximately 1,300 ft. It should be noted that a bus stop consolidation plan must also consider other issues such as land use, other travel alternatives, the history and development of a neighborhood, and demographics. 

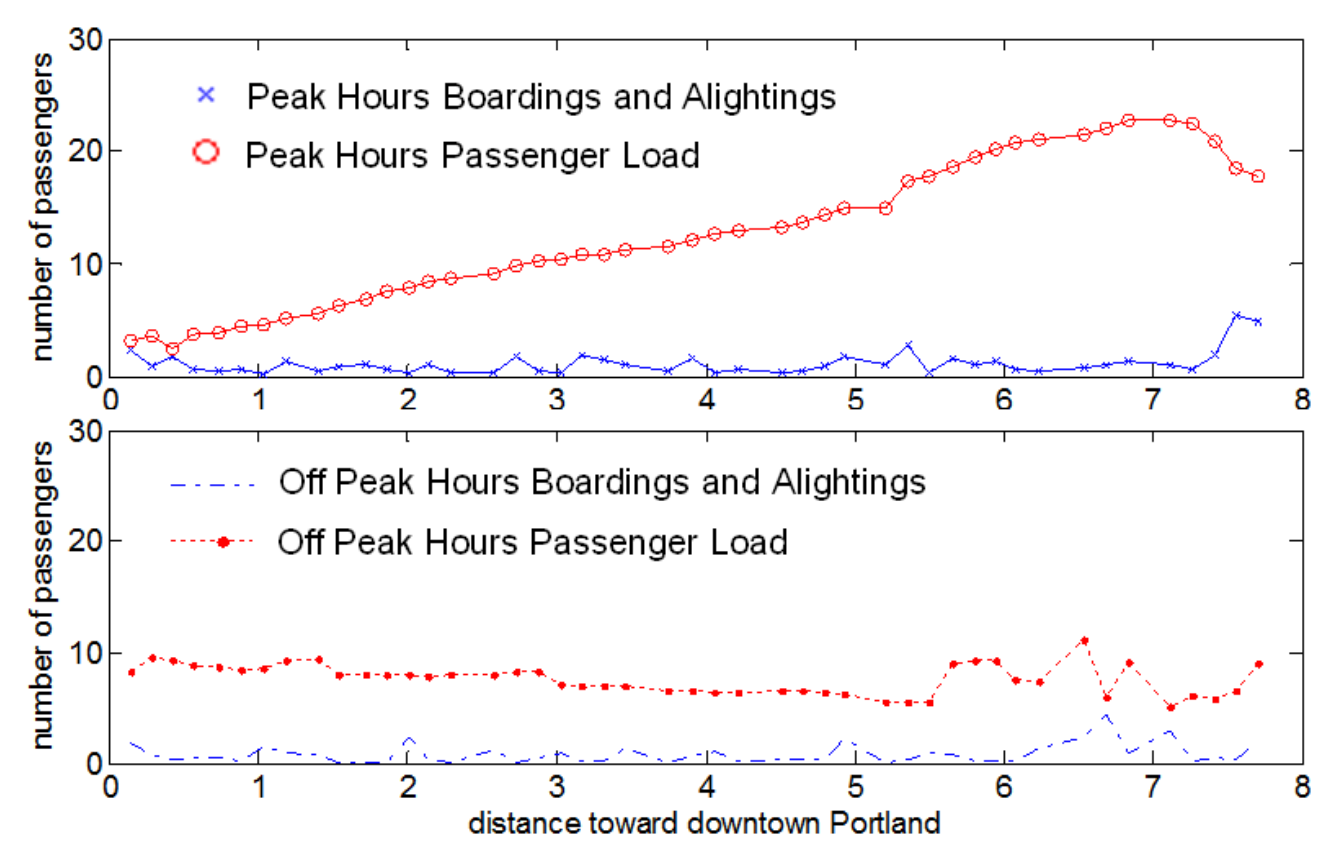

(a) Inbound route passenger load and ons\&offs
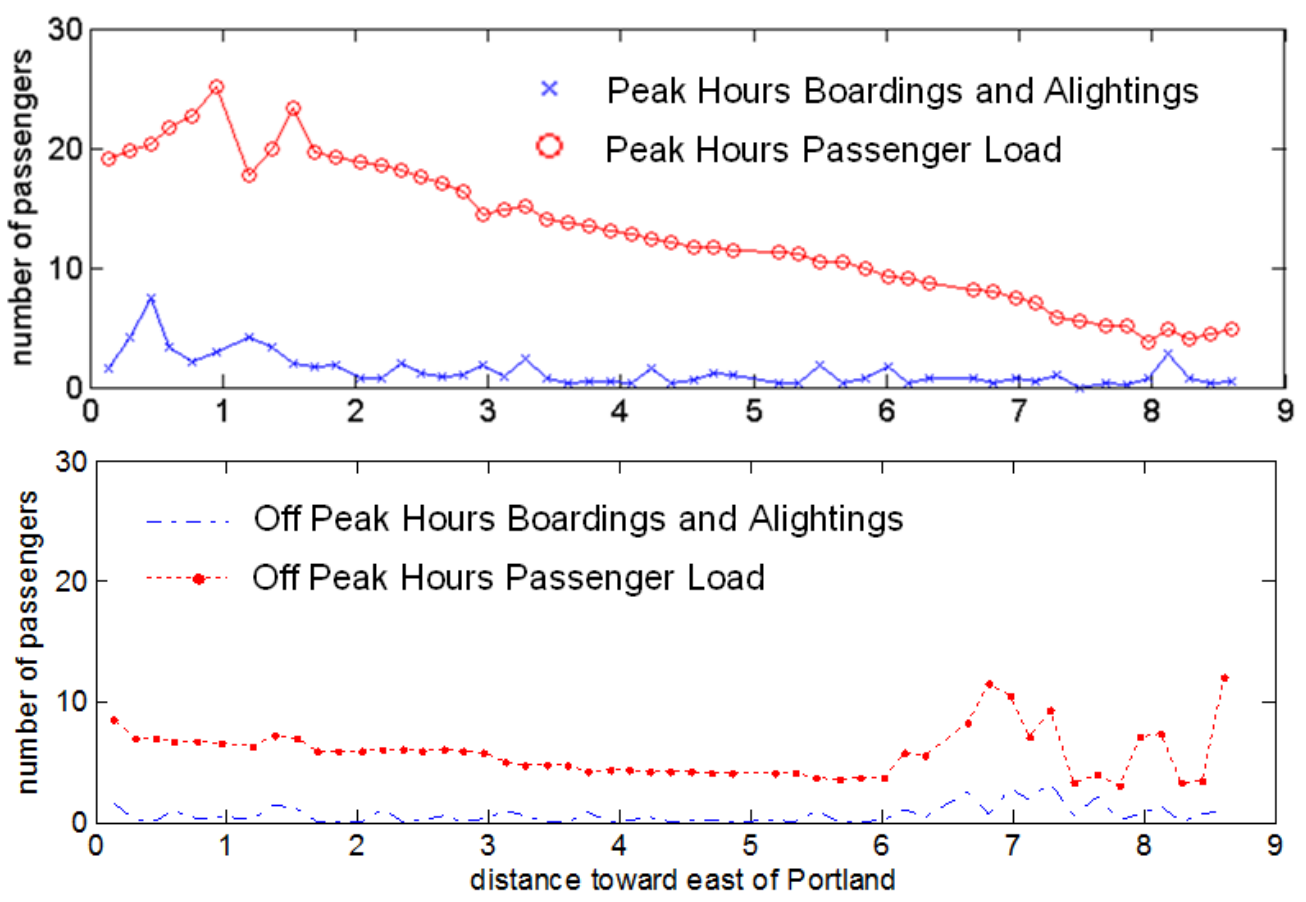

(b) Outbound route

FIGURE 20 A comparison of peak hours and off peak hours for spatial distribution of passenger activities for both inbound and outbound Route 19. 
Inbound Route Stop Locations

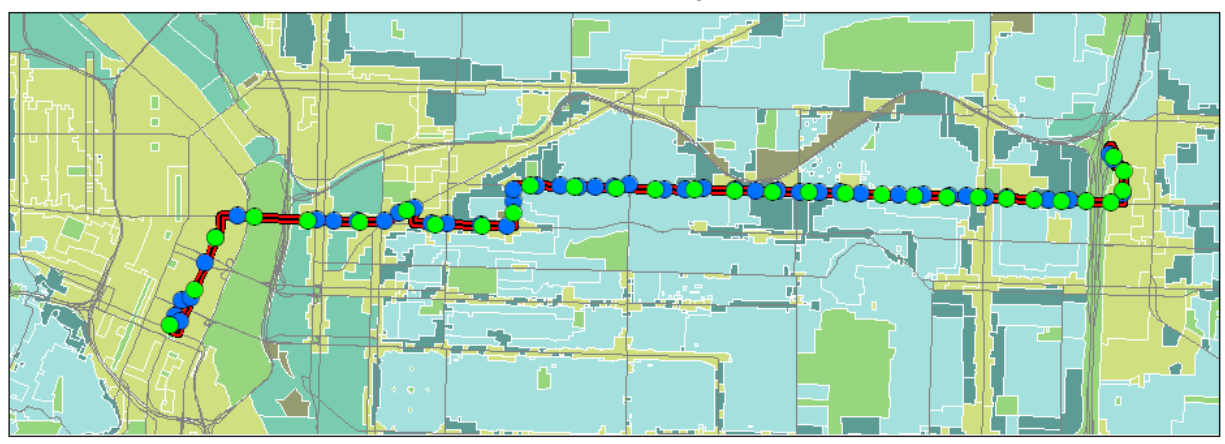

Outbound Route Stop Locations

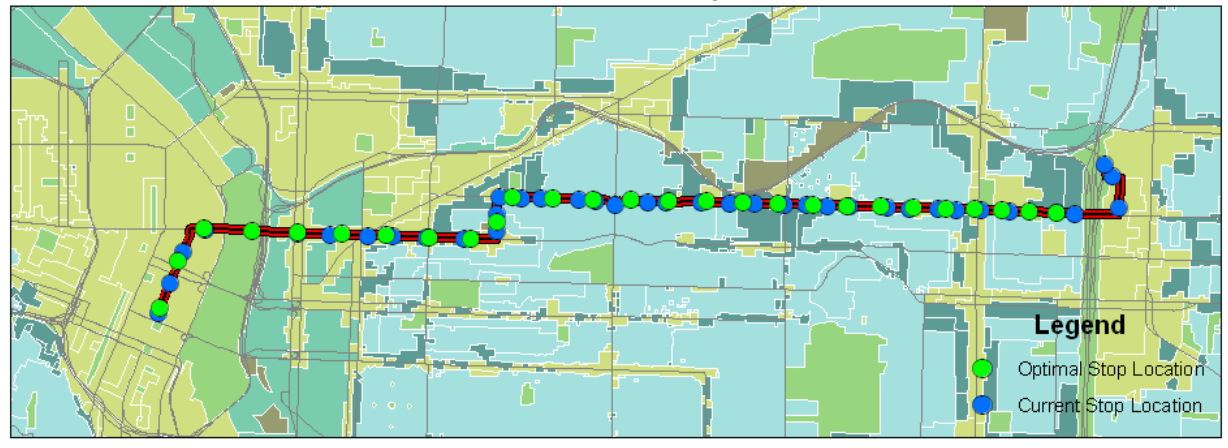

FIGURE 21 Optimal bus stop locations.

\subsection{BENEFIT COST ANALYSIS}

The application of the optimal stop spacing model has resulted in a possibility of removing or consolidating twelve bus stops for Route 19, considering the desire to minimize user cost. It is now possible to examine the impact of the input parameters on the cost of providing transit service. In general, from TriMet's perspective, consolidating stops is one strategy that can be used to reduce operating cost. In order to identify the time saved due to bus stop consolidation, a basic trip time model (19) is used here: 


$$
T=T_{0}+a N_{d}+b N_{a}+c N_{b}
$$

Where:

$$
T_{\mathrm{o}}=\text { Average nonstop trip time of a bus; }
$$

$N_{d}=$ Number of times a bus stops (dwells);

$N_{a}=$ Total number of passengers alighting a bus;

$N_{b}=$ Total number of passengers boarding a bus.

As a function of time lost for bus maneuvering in and out of a bus stop and the number of passenger boardings and alightings, the trip time model is able to provide time saved for removal of a bus stop without reducing time for serving a passenger on and off, that is, the coefficient parameter $a$. This is shown in Table 8 as time saved per stop. The benefits and costs of optimizing bus stop locations are estimated as shown in Table 8 . Based on the trip time model, with the average inbound Route 19 trip time of $29.5 \mathrm{~min}$, the time saved solely due to acceleration and deceleration would be $23.1 \mathrm{sec}$ per stop. With this savings, the trip time of each inbound trip for this route would be reduced by $5.4 \mathrm{~min}$ to $24.1 \mathrm{~min}$ after 14 stops are removed or consolidated. For the total of 17,076 inbound trips analyzed over a one year period, the time saved would be about 1,524 hours during the year. Using a basic assumption of a $\$ 60 / \mathrm{hr}$ operating cost, about $\$ 100,000$ per year could be saved by TriMet due to stop consolidation for inbound Route 19. Accordingly, the 
optimization on the outbound route has a potential of $\$ 180,000$ in savings. It is possible to assess a potential system wide operations cost savings for the entire year using this approach. These cost savings are hypothetical and might not be translatable to real savings, since, for example, headways may be set by policy.

These hypothetical time savings could be used improve service by adding more trips. Given that TriMet provides 66 scheduled inbound trips per weekday on inbound Route 19, the total savings due to consolidation could be up to 5.9 hours of service time per day. Without performing a complete operational analysis, this could allow the addition of approximately 12 additional trips per weekday on inbound Route 19. This would result in improved headways, whereby the mean weekday headway would drop from $18.0 \mathrm{~min}$ to $15 \mathrm{~min}$. Likewise, for outbound Route 19 , the headway could be reduce to $15 \mathrm{~min}$ as well.

\section{TABLE 8 Operation cost.}

\begin{tabular}{|c|c|c|c|c|c|c|c|}
\hline & \multicolumn{4}{|c|}{ Time Saved Per: } & \multirow{2}{*}{$\begin{array}{l}\text { Added Trips } \\
\text { Per Day }\end{array}$} & \multirow{2}{*}{ Headway } & \multirow{2}{*}{$\begin{array}{l}\text { Operation Cost } \\
\text { Saved Per Year }\end{array}$} \\
\hline & Stop & Trip & Day & Year & & & \\
\hline Inbound & $23.1 \mathrm{~s}$ & $5.4 \mathrm{~min}$ & $5.9 \mathrm{hr}$ & $1524 \mathrm{hr}$ & 12 & $15 \mathrm{~min}$ & $\$ 100,000$ \\
\hline Outbound & $43.3 \mathrm{~s}$ & $9.4 \mathrm{~min}$ & $10.2 \mathrm{hr}$ & $3025 \mathrm{hr}$ & 17 & $15 \mathrm{~min}$ & $\$ 180,000$ \\
\hline
\end{tabular}

The benefits and costs are also analyzed from the user perspective. As illustrated in the stop spacing model in the previous section, the optimized spacing is related to the ratio of the value of access time to that of riding time. Table 9 contains a sensitivity analysis on this point. 
TABLE 9 Sensitivity analysis for the optimized spacing based on peak hour analysis on both inbound and outbound Route 19.

\begin{tabular}{|c|c|c|c|c|c|c|c|}
\hline & & \multicolumn{3}{|c|}{ Inbound } & \multicolumn{3}{|c|}{ Outbound } \\
\hline & $\gamma_{r} / \gamma_{a}$ & $1 / 2$ & $1 / 3$ & $1 / 4$ & $1 / 2$ & $1 / 3$ & $1 / 4$ \\
\hline & $\begin{array}{r}\text { Optimized } \\
\text { Spacing }(\mathrm{ft})\end{array}$ & 1963 & 1603 & 1388 & 1819 & 1485 & 1286 \\
\hline \multirow{4}{*}{$\begin{array}{r}\text { Access } \\
\text { Cost }\end{array}$} & $\begin{array}{r}\text { Value of access time } \\
(\$ / \mathrm{hr})\end{array}$ & $\$ 16 / \mathrm{hr}$ & $\$ 18 / \mathrm{hr}$ & $\$ 20 / \mathrm{hr}$ & $\$ 16 / \mathrm{hr}$ & $\$ 18 / \mathrm{hr}$ & $\$ 20 / \mathrm{hr}$ \\
\hline & $\begin{array}{r}\text { Before optimized } \\
\text { (passenger \$/unit length) }\end{array}$ & $\$ 0.84$ & $\$ 0.94$ & $\$ 1.05$ & $\$ 0.93$ & $\$ 1.04$ & $\$ 1.16$ \\
\hline & $\begin{array}{r}\text { After optimized } \\
\text { (passenger \$/unit length) }\end{array}$ & $\$ 1.86$ & $\$ 1.71$ & $\$ 1.64$ & $\$ 1.89$ & $\$ 1.74$ & $\$ 1.67$ \\
\hline & $\begin{array}{r}\text { Change } \\
\text { (passenger \$/unit length) }\end{array}$ & +1.02 & +0.76 & +0.59 & +0.97 & +0.70 & +0.51 \\
\hline \multirow{4}{*}{$\begin{array}{r}\text { Riding } \\
\text { Cost }\end{array}$} & Value of riding time & $\$ 8 / \mathrm{hr}$ & $\$ 6 / \mathrm{hr}$ & $\$ 5 / \mathrm{hr}$ & $\$ 8 / \mathrm{hr}$ & $\$ 6 / \mathrm{hr}$ & $\$ 5 / \mathrm{hr}$ \\
\hline & $\begin{array}{r}\text { Before optimized } \\
\text { (passenger \$/unit length) }\end{array}$ & $\$ 2.43$ & $\$ 1.82$ & $\$ 1.52$ & $\$ 2.50$ & $\$ 1.87$ & $\$ 1.56$ \\
\hline & $\begin{array}{r}\text { After optimized } \\
\text { (passenger } \$ / \text { unit length) }\end{array}$ & $\$ 1.63$ & $\$ 1.38$ & $\$ 1.25$ & $\$ 1.72$ & $\$ 1.46$ & $\$ 1.32$ \\
\hline & $\begin{array}{r}\text { Change } \\
\text { (passenger \$/unit length) }\end{array}$ & -0.80 & -0.44 & -0.27 & -0.78 & -0.41 & -0.24 \\
\hline
\end{tabular}

Increased stop spacing after optimization would need to be balanced carefully against the additional walking/access distance for some passengers and the negative prospect of removing bus stops. Any stop consolidation decision would need to take into account existing passenger activity and land use patterns. In this session, the sensitivity of bus stop movement is tested. It could be used as a reference to represent how much the bus stop consolidation program improves the transit service for passengers. 


\section{CONCLUSIONS}

Transit operators face the challenging task of increasing farebox revenue to offset operating deficits while minimizing impacts on passenger accessibility. In order to provide a useful basis for bus stop consolidation, an optimal bus stop spacing model is applied in this paper based on minimizing access cost and riding cost. This stop spacing exercise has been developed for all day and peak hour separately. The all day analysis considered inbound Route 19 along Glisan St. to Downtown Portland over an entire day's operation, the result showed that 1,222 feet stop spacing is the optimal value for this inbound transit route. However, in order to emphasize the peak hour demand, the analysis was also performed for peak hour transit demand. Then, this paper examined inbound and outbound peak operations that the optimal spacing for inbound trips turned out to be 1,388 feet. Likewise, the stop spacing for outbound route is 1,286 feet based on the peak hour demand.

The archived BDS data provided by TriMet was used to perform the evaluation. According to the model calculations, the theoretical average spacing is 1,300 feet, two blocks longer than the current mean spacing. Based on a benefit/cost assessment, there is a potential for a $\$ 280,000$ reduction in annual operating cost for this route. Similarly, the entire bus system's operating cost can be evaluated. The theoretical stop spacing value is provided for planners and decision-makers as a powerful performance metric. Future research should continue to exploit the valuable archived BDS data. Choices of stop location and stop 
consolidation programs should be carefully examined considering demographics and many other practical factors.

Future research that would be built on these results could include some modifications of the formulated model. Based on the field data analysis presented in this thesis, some assumptions are tested and the distribution of each variable are examined. These analysis could be included and be added in the formulation of the stop spacing model. The future works could include:

1. Modify the passenger load and passenger boardings and alightings variable with a distribution function instead of using the mean values. In other words, consider the standard deviation of passengers on the vehicle and boardings and alightings at a stop in the model.

2. Modify the arrival rate function with negative binomial distribution instead of Poisson distribution based on the BDS analysis.

3. Improve the bus stop deployment scheme in the reason that the presented optimal stop spacing is an average value for a route, that is, the model considers the attraction of the transit demand for a bus line instead of a bus stop as a point. For a single point demand attraction could be considered as next step.

4. Use census block information to see how much additional walking is added to every single person residing around the route. 
5. Combine all the information and take the optimization of spacing into account to investigate the effects on passenger activity and optimize in the number of people being served.

In conclusion, the future work could be generated for the goal of a generic methodology for bus stop consolidation that can use any type of data, either AVL or census, for any site and serves the entire system. 


\section{REFERENCES}

[1]. Furth, P., M. Mekuria, and J. SanClemente. Stop Spacing Analysis Using Geographic Information System Tools with Parcel and Street Network Data. In Transportation Research Record: Journal of the Transportation Research Board, No. 2034, Transportation Research Board of the National Academies, Washington, D.C., 2007, pp. 73-81.

[2]. Ammons, D. N. Municipal Benchmarks: Assessing Local Performance and Establishing Community Standards. Sage Publications, Thousand Oaks, CA, 2001.

[3]. Reilly, J.M. Transit Service Design and Operation Practices in Western European Countries. In Transportation Research Record: Journal of the Transportation Research Board, No. 1604, Transportation Research Board of the National Academies, Washington, D.C., 1997, pp. 3-8.

[4]. Benn, H. Bus Route Evaluation Standards. Presented at the 74th Annual Meeting of the Transportation Research Board, Washington D.C., 1995.

[5]. Furth, P. and A. Rahbee. Optimal Bus Stop Spacing Through Dynamic Programming and Geographic Modeling. In Transportation Research Record: Journal of the Transportation Research Board, No. 1731, Transportation Research Board of the National Academies, Washington, D.C., 2000, pp.15-22.

[6]. Texas Transportation Institute. Guidelines for the Location and Design of Bus Stops, Transit Cooperative Research Program (TCRP) Report 19, 
Transportation Research Board, Washington, D.C., 1996.

[7]. Transportation Research Board. Bus Route and Schedule Guidelines, National Cooperative Highway Research Program (NCHRP) Synthesis of Highway Practice No. 69, Transportation Research Board, Washington D.C., 1980.

[8]. Saka, A. Model for Determining Optimum Bus-Stop Spacing in Urban Areas. Journal of Transportation Engineering, Vol. 127, No. 3, May/June 2001, pp.195-199.

[9]. El-Geneidy, A., J. Strathman, T. Kimpel and D. Crout. The Effect of Bus Stop Consolidation on Passenger Activity and Transit Operations. In Transportation Research Record: Journal of the Transportation Research Board, No. 1971, Transportation Research Board of the National Academies, Washington, D.C., 2006, pp. 32-41.

[10]. Newell, G.F. Lecture Notes on Public Transportation. University of California at Berkeley, 1994.

[11]. Wirasinghe, S.C. and N.S. Ghoneim. Spacing of bus stop for many to many travel demand. Transportation Science, Vol. 15, No. 3, 1981, pp. 210-221.

[12]. Murray, A. A Coverage Model for Improving Public Transit System Accessibility and Expanding Access. Annals of Operations Research, Vol. 123, No. 1, 2003, pp. 143-156.

[13]. Van Nes, R. and P.H. Bovy. Importance of Objectives in Urban Transit Network Design. In Transportation Research Record: Journal of the 
Transportation Research Board, No. 1735, Transportation Research Board of the National Academies, Washington, D.C., 2000, pp. 25-34.

[14]. Vuchic, V. and G. Newell. Rapid Transit Interstation Spacings for Minimum Travel Time. Transportation Science, Vol. 2, No. 2, 1968, pp. $303-339$.

[15]. Chien, S.I., Z. Qin, and R. Liu. Optimal Bus Stop Locations for Improving Transit Accessibility. Presented at the 82nd Annual Meeting of the Transportation Research, Washington, D.C., 2003.

[16]. Kuah, G.K. and J. Perl. Optimization of Feeder Bus Routes and Bus Stop Spacing. Journal of Transportation Engineering, Vol. 114, No. 3, 1988, pp. $341-354$.

[17]. Murray, A. and X. Wu. Accessibility Tradeoffs in Public Transit Planning. Journal of Geographical Systems, Vol. 5, No. 1, 2003, pp. 93-107.

[18]. Kittelson \& Associates, Transit Capacity and Quality of Service Manual. U.S. Department of Transportation, Washington, D.C., 2003.

[19]. Bertini, R. L. and A. El-Geneidy. Modeling Transit Trip Time using Archived Bus Dispatch System Data. Journal of Transportation Engineering, Vol. 130, No. 1, January/February 2004, pp. 56-67.

[20]. Berkow, M., J. Chee, R. L. Bertini, and C. Monsere. Transit Performance Measurement and Arterial Travel Time Estimation Using Archived AVL Data. Presented at the ITE District 6 Annual Meeting, July 2007.

[21]. Bertini, R.L. and A. El-Geneidy. Using Archived Data to Generate Transit 
Performance Measures. In Transportation Research Record: Journal of the Transportation Research Board, No. 1841, Transportation Research Board of the National Academies, Washington D.C., 2003, pp. 109-119.

[22]. Tri-County Metropolitan District of Oregon. TriMet Service Standards, Portland, OR, 1989.

[23]. Saka, A.A. Effect of Bus Stop Spacing on Mobile Emissions in Urban Areas. Presented at the 82nd Annual Meeting of the Transportation Research Board, Washington, D.C., 2003.

[24]. TDM Encyclopedia. Victoria Transport Policy Institute. http://www.vtpi.org/tdm/tdm62.htm\#_Toc135020075

[25]. Kemp, M A. Simultaneous-Equations Analysis of Growth in Bus Route Patronage in San Diego. Transportation Research Record 1982. No. 877: p.58-63.

[26]. Ercolano, J M. Limited-Stop Bus Operations: An Evaluation. In Transportation Research Record: Journal of the Transportation Research Board, No.994, Transportation Research Board of the National Academies, Washington D.C., 1984, pp.24-29

[27]. Bus Stop Placement in San Francisco. San Francisco Municipal Transportation Agency. http://friendlystreets.org/western_stac/docs/workshop06/presentation_patrin ick.pdf 